\title{
An effective stress framework for estimating penetration resistance accounting for changes in soil strength from maintained load, remoulding and reconsolidation
}

\author{
Z. ZHOU*, D. J. WHITE† and C. D. O’LOUGHLIN $\dagger$
}

\begin{abstract}
Some offshore foundations are subjected to intermittent episodes of remoulding and reconsolidation during installation and operational processes. The maintained and cyclic loads, and subsequent reconsolidation processes, cause changes in the geotechnical capacity, particularly in soft clays. This changing capacity affects the in-service behaviour, including changes to the safety margin, the extraction resistance, the stiffness and structural fatigue rates and also the overall system reliability. This paper provides a new analysis framework to capture these effects, based on estimation of the changing soil strength. The framework is developed using critical state concepts in the effective stress domain, and by discretising the soil domain as a one-dimensional column of soil elements. This framework is designed as the simplest basis on which to capture spatially varying changes in strength due to maintained and cyclic loads, and the associated remoulding and reconsolidation processes. The framework can be used to interpret cyclic penetrometer tests, as well as foundation behaviour. This provides a basis for the approach to be used in design, by scaling directly from penetrometer tests to foundation behaviour. Centrifuge tests are used to illustrate the performance of this approach. The penetration resistance during cyclic T-bar penetrometer tests and spudcan footing installation with periods of maintained loading and consolidation is accurately captured. The framework therefore provides a basis to predict the significant changes in penetration resistance caused by changing soil strength, and can bridge between in situ penetrometer tests and design assessments of soil-structure interaction.
\end{abstract}

KEYWORDS: clays; consolidation; offshore engineering; shear strength; soil/structure interaction

\section{INTRODUCTION}

\section{Background and motivation}

Several offshore geotechnical processes related to offshore foundations involve periodic cycles of remoulding and reconsolidation. The weakening effect of cyclic loading on the strength of soft soil is well recognised in design practice, and methodologies for determining the cyclic 'fatigue' of clay during undrained cyclic loading are well established (Andersen et al., 1988; Andersen, 2015). However, undrained capacity assessments often neglect the effects of drainage and consolidation that will inevitably occur in practice after installation and through long-term operations. This overlooked effect of consolidation on clay strength and geotechnical capacity can be important and beneficial for design practice.

For instance, during footing installations for mobile offshore drillings rigs, periods of consolidation under an elevated preload may be introduced deliberately to enhance the subsequent capacity (Amodio et al., 2015), and consolidation during the operational phase also affects the

Manuscript received 22 August 2017; revised manuscript accepted 15 February 2018.

Discussion on this paper is welcomed by the editor.

Published with permission by the ICE under the CC-BY 4.0 license. (http://creativecommons.org/licenses/by/4.0/)

* Centre for Offshore Foundation Systems and ARC Research Hub for Offshore Floating Facilities, University of Western Australia, Perth, WA, Australia (Orcid:0000-0002-3575-8810).

$\dagger$ Centre for Offshore Foundation Systems and ARC Research Hub for Offshore Floating Facilities, University of Western Australia, Perth, WA, Australia. subsequent extraction resistance (Purwana et al., 2005; Kohan et al., 2014, 2016). Through the consolidation period, the recovery of soil strength enhances the penetration resistance, which may raise the capacity to an acceptable level that would enhance the range of wave conditions in which the jack-up can safely operate. Conversely, this rise in capacity may hamper extraction of the legs on completion of drilling.

Similarly, all subsea foundations and anchoring systems are subjected to some level of cyclic loading throughout their life, either from day-to-day cycles of operating temperature in the connected pipelines and equipment, or from mild sea states. These cyclic episodes are sustained over a significantly longer period than a single storm and will progressively strengthen the surrounding soft clay through drainage and consolidation.

Currently, most of the published studies to analyse and quantify the increased soil resistance owing to consolidation focus on shallow foundations, in which significant remoulding and gross vertical movements of the foundation do not occur (Bransby, 2002; Lehane \& Jardine, 2003; Bienen et al., 2010; Gourvenec \& Randolph, 2010; Gourvenec et al., 2014; $\mathrm{Fu}$ et al., 2015). In this situation, it is not necessary to consider either remoulding, or the movement of the foundation relative to the strengthened zone of soil, and so analysis methods using a single 'lumped' value of changing soil strength are used (Gourvenec et al., 2014, 2017).

The next level of sophistication is to idealise the soil domain by way of a one-dimensional vertical discretisation. This is akin to the oedometer method of settlement estimation, in which soil layers beneath the foundation may be assigned different compression indices. Hodder et al. (2013) used a one-dimensional discretisation to analyse the remoulding and reconsolidation processes in a cyclic 
penetrometer test, with the device moving vertically through the layers. Corti et al. (2017) and Cocjin et al. (2017) analysed sliding surface foundations using the same form of discretisation, with the foundation applying varying levels of shear stress to the different layers.

Extending these previous contributions, this paper sets out a new analytical framework for estimating soil resistance during penetration processes that cause changes in soil strength. The major purpose of the framework is to establish a theoretical tool for quantifying the changing soil resistance considering the combined effects of remoulding and reconsolidation. A potential use of the framework is to bridge between advanced in situ tests and predictions for foundation design, as illustrated in Fig. 1.

\section{Analytical concept of framework}

The new framework stems from an idea highlighted by Palmer (1997) and extends a basic framework established by Hodder et al. (2013) for predicting the vertical forcedisplacement response of an object moving in clay. The significant extensions from the previous work (as outlined in Table 1) are given below.

(a) The framework is defined with sufficient generality that it can be applied to scenarios that are load-controlled, displacement-controlled or a mixed sequence, which allows realistic simulation of 'whole-life' cyclic loading histories. (b) A one-component model is developed to quantify the generation of excess pore pressure as a function of disturbance. Instead of counting loading cycles, the excess pore pressure generation is linked to the accumulation of shear strain during an undrained penetration and remoulding process. This approach is based on techniques first developed for the T-bar penetrometer by Einav \& Randolph (2005).

(c) A simple hyperbolic function is introduced to characterise the excess pore pressure dissipation at each soil horizon.

(d) The variation in soil strength considering remoulding, reconsolidation and maintained load is captured by changes in applied vertical load and excess pore pressure, which together define the vertical effective stress and thereafter the undrained shear strength.

(e) A non-linear mobilisation of the strength and limiting resistance is used, creating the variation in stiffness and allowing both load-controlled and displacement-controlled events to be modelled.

Before these analytical components are introduced, results from two sets of geotechnical centrifuge test are shown, which are later used for validation of the framework. In the experiments, a T-bar penetrometer (Stewart \& Randolph, 1991) and a spudcan footing typical of a mobile jack-up

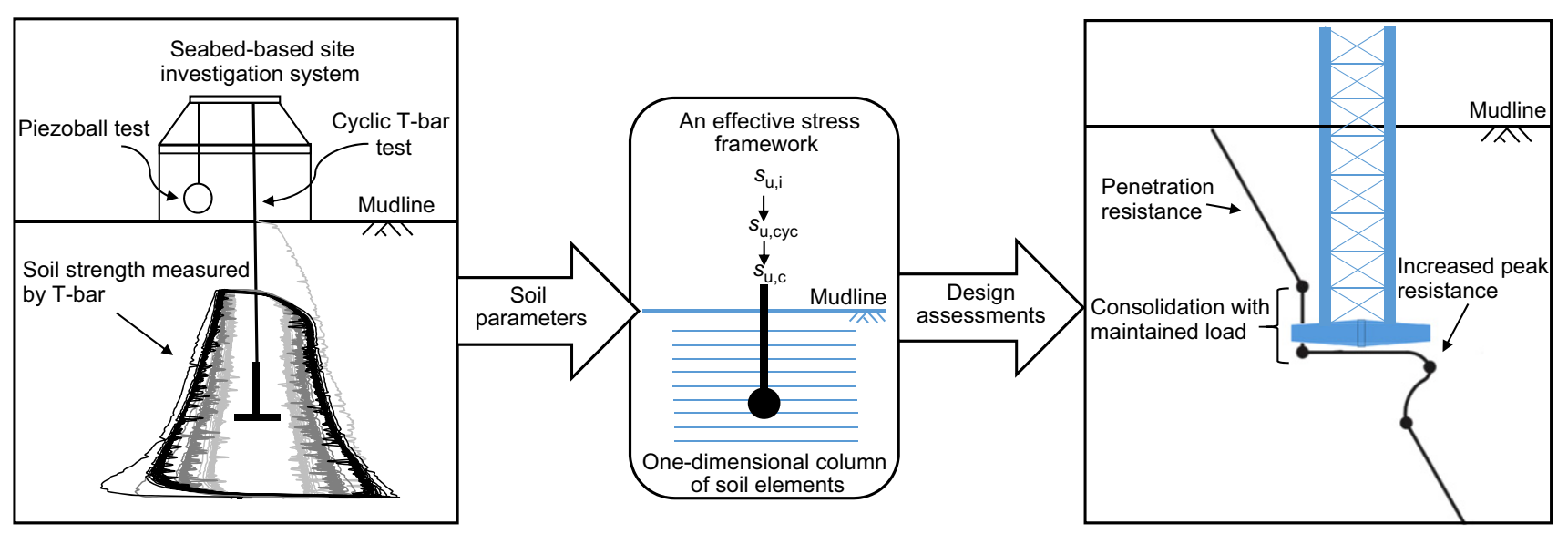

Fig. 1. A potential application of the framework to bridge between in situ tests and foundation design

Table 1. Notable extensions of Hodder et al. (2013) framework

\begin{tabular}{|c|c|c|}
\hline Framework component & $\begin{array}{l}\text { Model framework, Hodder } \\
\text { et al. (2013) }\end{array}$ & Present model framework \\
\hline \multicolumn{3}{|l|}{ Types of analysis (operation) } \\
\hline Displacement-controlled operation & Applicable & Applicable \\
\hline Load-controlled operation & N/A & Applicable \\
\hline Complex-controlled operation & N/A & Applicable \\
\hline \multicolumn{3}{|l|}{ Components of analysis } \\
\hline Concept & Critical state concept & Critical state concept \\
\hline General cyclic strength response & By vertical effective stress & By vertical effective stress \\
\hline Excess pore pressure generation & By cycle number & By cumulative shear strain \\
\hline $\begin{array}{l}\text { Consolidation process including maintained } \\
\text { load }\end{array}$ & N/A & Applicable \\
\hline $\begin{array}{l}\text { Excess pore pressure dissipation function } \\
\text { (built-in consolidation analysis) }\end{array}$ & $\begin{array}{l}\text { One-dimensional dissipation } \\
\text { in lateral direction }\end{array}$ & $\begin{array}{l}\text { A simple hyperbolic function for excess pore pressure } \\
\text { dissipation }\end{array}$ \\
\hline Mobilisation of strength & $\begin{array}{l}\text { A simple exponential } \\
\text { expression }\end{array}$ & $\begin{array}{l}\text { A non-linear model considering a changing tangent } \\
\text { stiffness varied by cyclic undrained shearing and } \\
\text { reconsolidation }\end{array}$ \\
\hline
\end{tabular}


platform were used in a series of penetration tests. The results of the cyclic T-bar penetration test reveal the soil strength variation during cyclic loading and reconsolidation, while the spudcan penetration test illustrates the variation in penetration resistance at foundation scale, and particularly highlights the effect of the magnitude and duration of the maintained load on the subsequent penetration resistance. The paper closes by comparing framework simulations against the results of the two centrifuge tests.

\section{EXPERIMENTAL OBSERVATIONS OF REMOULDING AND CONSOLIDATION \\ Effects on T-bar penetration resistance}

A special suite of T-bar tests was carried out to explore and quantify soil strength degradation owing to cyclic penetration and subsequent regain after reconsolidation, using the beam centrifuge at the University of Western Australia.

The cyclic T-bar tests were performed in a lightly overconsolidated kaolin clay, and were reported previously by Hodder et al. (2009). Kaolin slurry with a water content equal to twice the liquid limit was normally consolidated in the centrifuge at $50 \mathrm{~g}$ for 4 days. The centrifuge was then stopped and approximately $45 \mathrm{~mm}$ of clay was scraped from the surface of the sample prior to testing. A T-bar penetrometer (Stewart \& Randolph, 1991) with a diameter of $5 \mathrm{~mm}$ and a length of $50 \mathrm{~mm}$ was used to determine depth profiles of intact and remoulded shear strength.

The T-bar test consisted of three episodes of 20 cycles, all of which were conducted at the same location in the sample. In each cycle, the bar was penetrated between depths of 15 and $60 \mathrm{~mm}(0.75 \mathrm{~m}$ and $3 \mathrm{~m}$ at prototype scale, respectively) with a vertical displacement rate of $1 \mathrm{~mm} / \mathrm{s}$ (at model scale) to ensure undrained conditions. A consolidation period of $3.5 \mathrm{~h}$ was permitted between each cyclic episode. Profiles of undrained shear strength, $s_{\mathrm{u}}$, with depth, $z$, are provided in Fig. 2(a), and were calculated from the penetration resistance, $q_{\mathrm{r}}$, as $s_{\mathrm{u}}=q_{\mathrm{r}} / N_{\mathrm{c}}$, using a bearing capacity factor, $N_{\mathrm{c}}=10 \cdot 5$, as appropriate for a T-bar (Martin \& Randolph, 2006). Within each episode of cycles the strength reduced - due to remoulding - whereas between episodes the strength increased - due to reconsolidation. These trends are illustrated in Fig. 2(b) by way of a degradation factor defined as DF $=s_{\mathrm{u}, \mathrm{cyc}} / s_{\mathrm{u}, \mathrm{i}}$ (where $s_{\mathrm{u}, \mathrm{cyc}}$ and $s_{\mathrm{u}, \mathrm{i}}$ are the cyclic and in situ undrained shear strength, respectively) based on the strength measured at a depth of $1.75 \mathrm{~m}$.

\section{Effects on spudcan footing penetration resistance}

A set of spudcan foundation penetration tests was conducted at $200 \boldsymbol{g}$ in the drum centrifuge facility at the University of Western Australia (Stewart et al., 1998); the tests were reported by Bienen \& Cassidy (2013). The model seabed consisted of normally consolidated kaolin clay, prepared in a similar manner as described for the T-bar tests. The model spudcan had a diameter of $D=60 \mathrm{~mm}$ (12 $\mathrm{m}$ at prototype scale) and was connected to an actuator that was used to penetrate and extract the spudcan, and to apply a constant vertical load to mimic a period of maintained loading.

A series of spudcan installations was carried out to a final depth of $120 \mathrm{~mm}$ (at model scale, equivalent to $2 \mathrm{D}$ ). The footing was initially penetrated into the soil at a fixed displacement rate of $0.2 \mathrm{~mm} / \mathrm{s}$ (at model scale), after which it was held under a specified maintained load close to a chosen target depth (either $0 \cdot 5,1 \cdot 0$ or $1 \cdot 5 D$ ). When the target depth
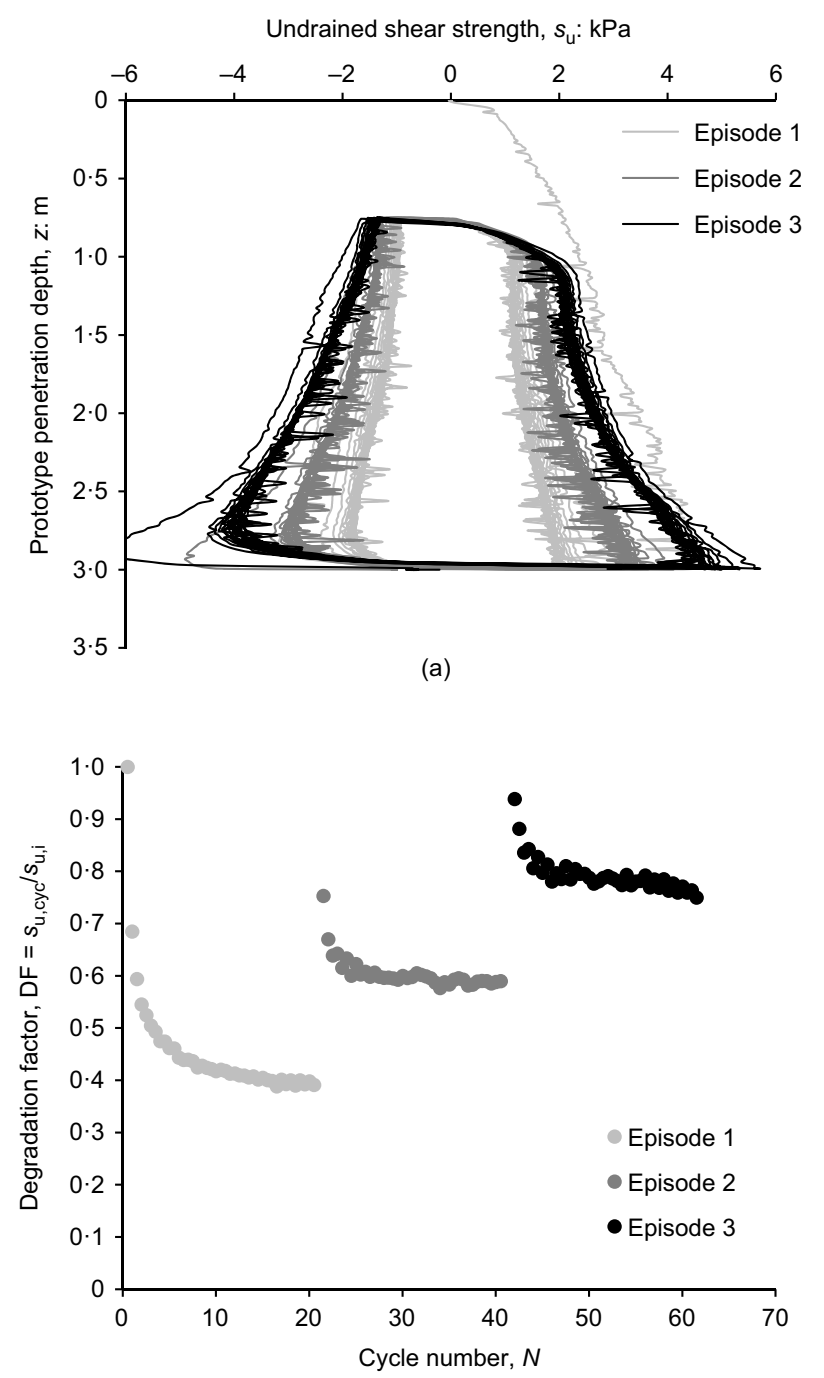

(b)

Fig. 2. Cyclic T-bar penetration test with reconsolidation between each episode (after Hodder et al. (2009)): (a) profile of undrained shear strength with depth; (b) degradation factor plotted against number of cycles

was reached, the actuator system was switched from displacement control to load control. The vertical load was held for a range of consolidation periods from $200 \mathrm{~s}$ to $4 \mathrm{~h}$ at model scale $(0 \cdot 25$ to 18 years at prototype scale, respectively). A further penetration stage was performed following the consolidation, at a rate of $0 \cdot 2 \mathrm{~mm} / \mathrm{s}$ (i.e. the same as adopted for the initial penetration). Further details of the apparatus and procedures are given by Bienen \& Cassidy (2013).

The spudcan penetration resistance is reported in Fig. 3 as a normalised penetration resistance, $q_{\mathrm{r}} / s_{\mathrm{u}, \mathrm{i}}$, where $s_{\mathrm{u}, \mathrm{i}}$ is the in situ undrained shear strength at the depth of the spudcan base (as derived from a T-bar test). Fig. 3 shows the measured variation in normalised penetration resistance for a range of consolidation times from $0 \cdot 25$ to 18 years (at prototype scale) at a target depth of $1 D$. The results show a trend of increasing penetration resistance with consolidation time, and reveal the zone of improved soil strength beneath the spudcan during subsequent penetration.

The two sets of experiments demonstrate the variation in penetration resistance caused by remoulding, reconsolidation and maintained load, and form an ideal initial database to 


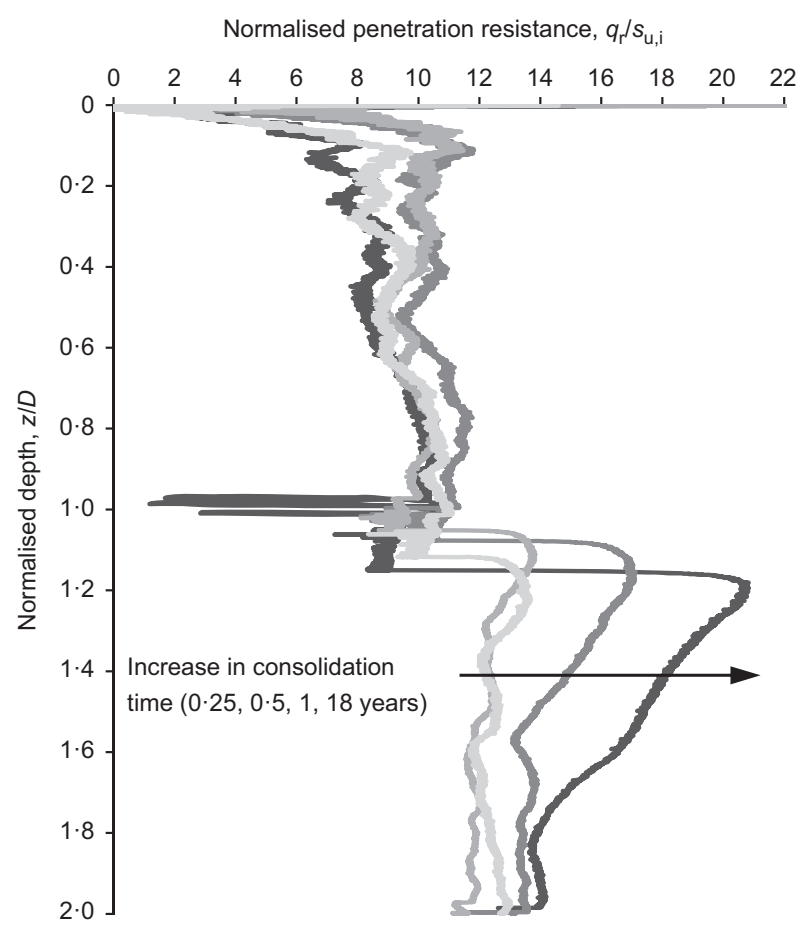

Fig. 3. Increase in bearing resistance due to consolidation at a normalised depth of $z I D \sim 1$ (after Bienen \& Cassidy, 2013)

examine the merit of the framework (described in the following section) in capturing such responses.

\section{ANALYSIS FRAMEWORK \\ Overview}

This overview introduces the nomenclature and components of the framework. A detailed description of each component is presented in following section.

The notation used to define a soil horizon, and the position and size of a penetrating object for penetration or extraction processes is shown in Fig. 4.

To define the strain on a given horizon that is mobilised as the penetrating object (in this case a cylindrical T-bar penetrometer) approaches and then passes a soil horizon, a strain influence zone is defined with boundaries extending a distance, $\beta$, above and below the object penetration depth, $\hat{z}_{\mathrm{m}}$. A full passage of a soil element entirely into and out of the zone results in a cumulative (absolute) shear strain

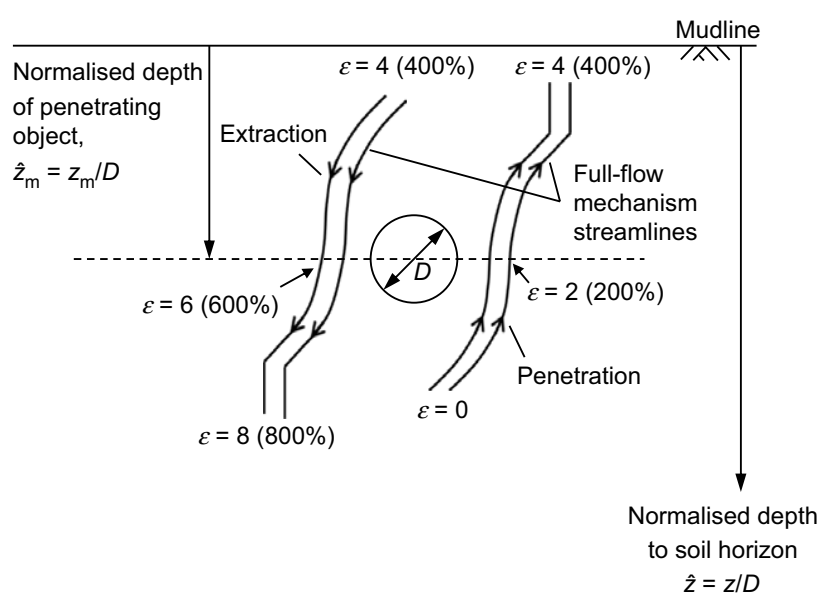

Fig. 4. Depth notation and average cumulative (absolute) shear strain for initial penetration and extraction increase of $\Delta \varepsilon=400 \%$ (based on Einav \& Randolph (2005)), as presented in Fig. 4.

An influence distribution function, $\mu(\hat{z})$, is used to calculate the incremental shear strain (per unit penetrometer displacement) within the strain influence zone. The incremental strain varies with the vertical distance, $\Psi$, between a soil horizon and the object penetration depth (shown in Figs 5(a) and 5(b)). Integration of this strain rate over the influence zone yields the total, $\Delta \varepsilon=400 \%$.

The changing soil strength at a given soil horizon is estimated according to Fig. 5. The excess pore pressure is denoted by $u_{\mathrm{e}}(\hat{z})$. As the object penetrates, excess pore pressure is generated at a rate dependent on the (absolute) shear strain rate (Fig. 5(c)).

The equilibrium vertical effective stress (i.e. the value in the absence of excess pore pressure) is initially geostatic $\left(\sigma_{\mathrm{v}, \text { eqm }}^{\prime}(\hat{z})=\gamma^{\prime} \hat{z}\right)$, but will vary as a maintained load is applied, which creates additional excess pore pressure. Under vertical compression loading, this increment in pore pressure will be positive beneath the foundation and a negative value may occur above it (Fig. 5(d)). During consolidation, positive excess pore pressure dissipation leads to a rise in vertical effective stress (Fig. 5(e)). This results in an increase in soil undrained shear strength (Fig. 5(f)).

The average soil strength 'felt' by the penetrating object is a smeared average of the local strength, which may vary between soil horizons. The strength is averaged within a strength influence zone (Fig. 5(h)), applying a weighting by way of a strength influence function, $v_{\mathrm{s}}(\hat{z})$, (Fig. 5(i)). As the object changes the direction of movement, the soil strength is mobilised progressively over a short distance (Fig. 5(j)). Once the average soil strength is calculated, it is converted to a limiting penetration resistance, $q_{\mathrm{r}}$, based on $q_{\mathrm{r}}=N_{\mathrm{c}} s_{\mathrm{u} \text {,av }}$ (Fig. 5(k)).

\section{Components of analysis}

Excess pore pressure generation from undrained shearing.

Excess pore pressure, $u_{\mathrm{e}}(\hat{z})$, results from undrained shearing and remoulding, based on the (absolute) shear strain rate at each soil horizon and the ratio between the remaining potential excess pore pressure, $u_{\mathrm{e}, \mathrm{r}}(\hat{z})$, and the maximum excess pore pressure, $u_{\mathrm{e} \text {, max }}(\hat{z})$, where these quantities are illustrated in Fig. 6. This approach causes the rate of excess pore pressure generation to asymptote to zero as the effective stress state approaches a fully remoulded strength line (RSL). The rate of excess pore pressure generation is expressed as

$$
\begin{aligned}
\frac{\delta u_{\mathrm{e}}(\hat{z})}{\delta \varepsilon(\hat{z})} & =\frac{\chi}{\varepsilon_{99}}\left[\frac{u_{\mathrm{e}, \mathrm{r}}(\hat{z})}{u_{\mathrm{e}, \max }(\hat{z})}\right]^{p} \\
& =\frac{\chi}{\varepsilon_{99}}\left[\frac{\sigma_{\mathrm{v}}^{\prime}(\hat{z})-\sigma_{\mathrm{v}, \mathrm{RSL}}^{\prime}(\hat{z})}{\sigma_{\mathrm{v}, \mathrm{NCL}}^{\prime}(\hat{z})-\sigma_{\mathrm{v}, \mathrm{RSL}}^{\prime}(\hat{z})}\right]^{p}
\end{aligned}
$$

where the stress and pore pressure values are as defined in Fig. 6. $\varepsilon_{99}$ is the characteristic shear strain associated with a degree of remoulding equal to $99 \%$ (meaning a $99 \%$ reduction in strength from initial to fully remoulded, for overconsolidation ratio, $\mathrm{OCR}=1) ; p$ is a constant power that affects the shape of the pore pressure generation; and $\chi$ is a characteristic pressure derived later that varies with specific volume.

The incremental cumulative (absolute) shear strain is calculated as the object penetrates with a given displacement, $\delta \hat{z}_{\mathrm{m}}$, and weighted by the strain influence function. It can be expressed as

$$
\delta \varepsilon(\hat{z})=4 \mu(\hat{z}) \delta \hat{z}_{\mathrm{m}}
$$




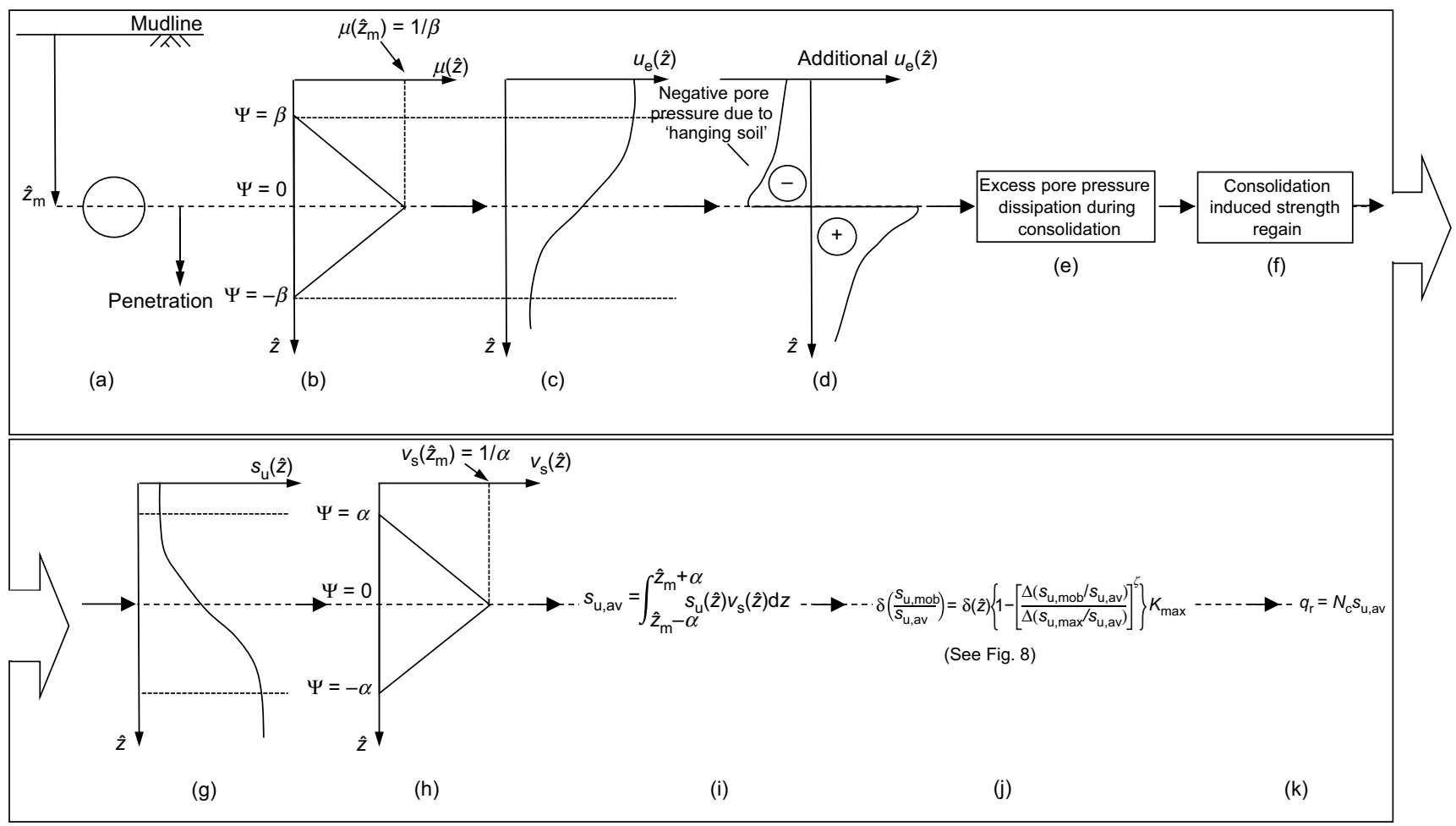

Fig. 5. Schematic representation of the model framework (extending Hodder et al., 2013): (a) current penetrating object location; (b) absolute shear strain influence zone; (c) current excess pore pressure distribution by penetration remoulding; (d) additional excess pore pressure generation due to maintained load; (e) excess pore pressure dissipation during consolidation; (f) consolidation-induced strength regain; (g) current undrained shear strength distribution; (h) strength influence zone; (i) average undrained shear strength at the object reference point; (j) mobilisation of undrained shear strength; (k) penetration resistance

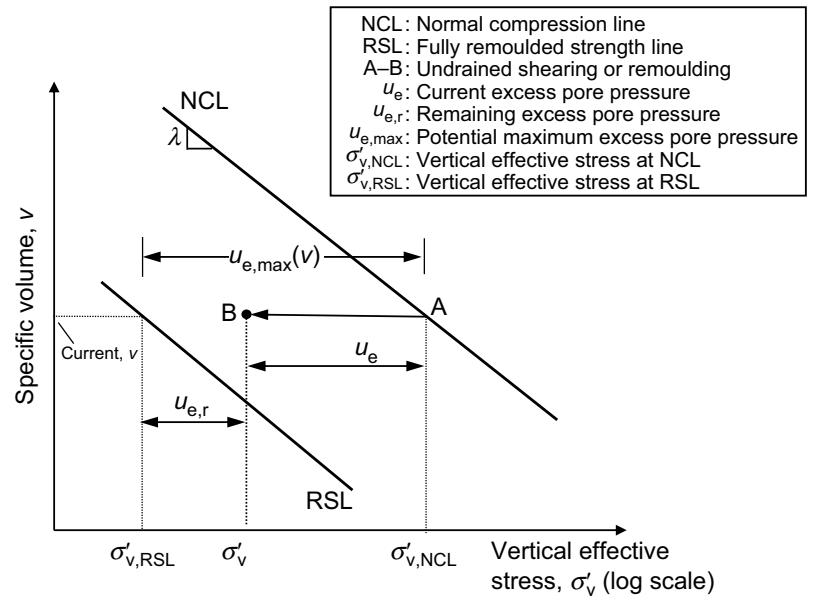

Fig. 6. Definition of maximum excess pore pressure

The influence distribution function, $\mu(\hat{z})$, decays linearly above and below the position of the object, is zero if a soil horizon is outside the zone and has an integral of unity (Fig. 5(b)). The value 4 is an average (absolute) shear strain as a soil element has undergone a full passage of the strain influence zone (based on Einav \& Randolph (2005)).

The excess pore pressure for a given strain level is estimated by integrating equation (1) with boundary conditions: $u_{\mathrm{e}}=0$ at $\varepsilon=0$ and $u_{\mathrm{e}}=0.99 u_{\mathrm{e}, \max }$ at $\varepsilon=\varepsilon_{99}$, which is given by

$$
u_{\mathrm{e}}(\hat{z})=u_{\mathrm{e}, \max }(\hat{z})-\sqrt[1-p]{\frac{\chi}{\varepsilon_{99}} \frac{(p-1) \varepsilon(\hat{z})}{\left[u_{\mathrm{e}, \max }(\hat{z})\right]^{p}}+\left[u_{\mathrm{e}, \max }(\hat{z})\right]^{1-p}}
$$

where

$$
\chi=\frac{\left(1-0 \cdot 01^{1-p}\right)}{1-p} u_{\mathrm{e}, \max }(\hat{z})
$$

By substituting equation (4) into equation (3), a simple one-component equation between $u_{\mathrm{e}}(\hat{z})$ and $\varepsilon(\hat{z})$ is given by

$$
u_{\mathrm{e}}(\hat{z})=u_{\mathrm{e}, \max }(\hat{z})\left[1-\sqrt[1-p]{1-\frac{\left(1-0 \cdot 01^{1-p}\right) \varepsilon(\hat{z})}{\varepsilon_{99}}}\right]
$$

This is a relatively simple equation for quantifying excess pore pressure due to shearing during undrained penetration. The power, $p$, controls the rate of excess pore pressure generation, which affects the degradation of soil strength simulated by the framework. For the same stress state (specific volume and vertical effective stress), the model gives a consistent rate of excess pore pressure generation related to the incremental shear strain.

Excess pore pressure generation from maintained load. Apart from the excess pore pressure developed by the penetration and remoulding process, $u_{\mathrm{e}}(\hat{z})$, an additional sustained excess pore pressure, $\Delta u_{\mathrm{e}}(\hat{z})$, is present afterwards when the foundation is subjected to a maintained load, $q$, where $q$ is defined relative to the in situ geostatic effective stress, $\sigma_{\mathrm{v} 0}^{\prime}(\hat{z})=\gamma^{\prime} \hat{z}$. This maintained load creates a distribution of vertical stress in the surrounding soil. On application of this load, the additional excess pore pressure is developed at the instant of the load being applied due to the low permeability, and dissipates with time. The spatial distribution of $\Delta u_{\mathrm{e}}(\hat{z})$ beneath a spudcan is quantified here using Boussinesq's approach for a circular loaded area. 
The maintained load on a buried foundation may be carried by a combination of the soil below (by way of compression) and above (by tension, or a reduction in compression). This may lead to a reduction in pore pressure above the object as well as an increase below it. An additional parameter, $\eta$, quantifies the proportion of the load that is transmitted by way of the upper part, meaning that for $\eta=0$ the maintained load is passed entirely through the base of the object, whereas for $\eta=1$ the object is entirely 'hanging' from the overlying soil. The excess pore pressure created when the maintained load is applied is therefore given as

$$
\Delta u_{\mathrm{e}}(\hat{z})= \begin{cases}{\left[\frac{1-\operatorname{sign}\left(v_{\mathrm{p}}\right)}{2}-\eta\right] q I_{\sigma},} & \hat{z}<\hat{z}_{\mathrm{m}} \\ {\left[\frac{1+\operatorname{sign}\left(v_{\mathrm{p}}\right)}{2}-\eta\right] q I_{\sigma},} & \hat{z} \geq \hat{z}_{\mathrm{m}}\end{cases}
$$

where $v_{\mathrm{p}}$ is the penetration velocity of the object, and therefore indicates the direction of $q$ ( $v_{\mathrm{p}}$ is positive for penetration and negative for extraction); $I_{\sigma}$ is the influence factor for vertical stress distribution under maintained load that can be estimated following Boussinesq (1885), albeit for elastic conditions, and is given by

$$
I_{\sigma}=1-\left[\frac{1}{1+(D / 2 \hat{z})^{2}}\right]^{3 / 2}
$$

Consolidation process. The consolidation analysis accounts for excess pore pressure dissipation. The 'packet' of excess pore pressure generated by each episode of undrained shearing or change in maintained load, $q$, is dissipated separately, with the subscript ' $i$ ' used to denote an individual packet. The dissipation response is assumed to follow a simple hyperbolic equation (Chatterjee et al., 2013; Cocjin et al., 2017), which can be expressed in rate form as

$$
\frac{\delta u_{\mathrm{e}}(\hat{z})}{\delta t}=-\frac{u_{\mathrm{e}, \mathrm{i}}\left(\hat{z}, t_{i}\right) c_{\mathrm{v}}^{m} t_{\mathrm{i}}^{m-1}\left(D^{2} T_{50}\right)^{m} m}{\left[\left(D^{2} T_{50}\right)^{m}+\left(c_{\mathrm{v}} t_{\mathrm{i}}\right)^{m}\right]^{2}}
$$

where $t_{\mathrm{i}}$ is a period of consolidation after each packet of excess pore pressure generation; $c_{\mathrm{v}}$ is coefficient of consolidation; $T_{50}$ is the non-dimensional time required for $50 \%$ dissipation of the initial excess pore pressure; and $m$ is a constant that controls the shape of the dissipation response.

Figure 7 illustrates the change in stress state (in the specific volume-stress plane) during consolidation. Dissipation of positive excess pore pressure results in a decrease in specific volume and a rise in vertical effective stress towards the equilibrium value (point $\mathrm{F}$ in Fig. 7). The changes in specific volume can be obtained from the variation in vertical effective stress, $\Delta \sigma_{\mathrm{v}}^{\prime}$ (equal to dissipation of excess pore pressure). With the effect of maintained load, the dissipation of excess pore pressure can lead to the effective stress state reaching the normal consolidation line (NCL), and the changes in specific volume are generally given by

$$
\Delta v(\hat{z})=-\kappa \ln \left[\frac{\sigma_{\mathrm{vc}}^{\prime}(\hat{z})}{\sigma_{\mathrm{v}}^{\prime}(\hat{z})}\right]-\lambda \ln \left[\frac{\sigma_{\mathrm{v}}^{\prime}(\hat{z})+\Delta \sigma_{\mathrm{v}}^{\prime}(\hat{z})}{\sigma_{\mathrm{vc}}^{\prime}(\hat{z})}\right]
$$

where $\sigma_{\mathrm{v}}^{\prime}$ is the vertical effective stress after undrained shearing or remoulding; $\sigma_{\mathrm{vc}}^{\prime}$ is the pre-consolidation stress; $\Delta \sigma_{\mathrm{v}}^{\prime}$ is the increase in effective stress from pore pressure dissipation; $\lambda$ is the gradient of the NCL; and $\kappa$ is the gradient of the unload-reload line (see Fig. 7).

Soil strength response. The soil strength is defined as proportional to the current vertical effective stress, $\sigma_{\mathrm{v}}^{\prime}(\hat{z})$, by way of a lumped strength parameter, $\Phi$

$$
s_{\mathrm{u}}(\hat{z})=\Phi \sigma_{\mathrm{v}}^{\prime}(\hat{z})
$$

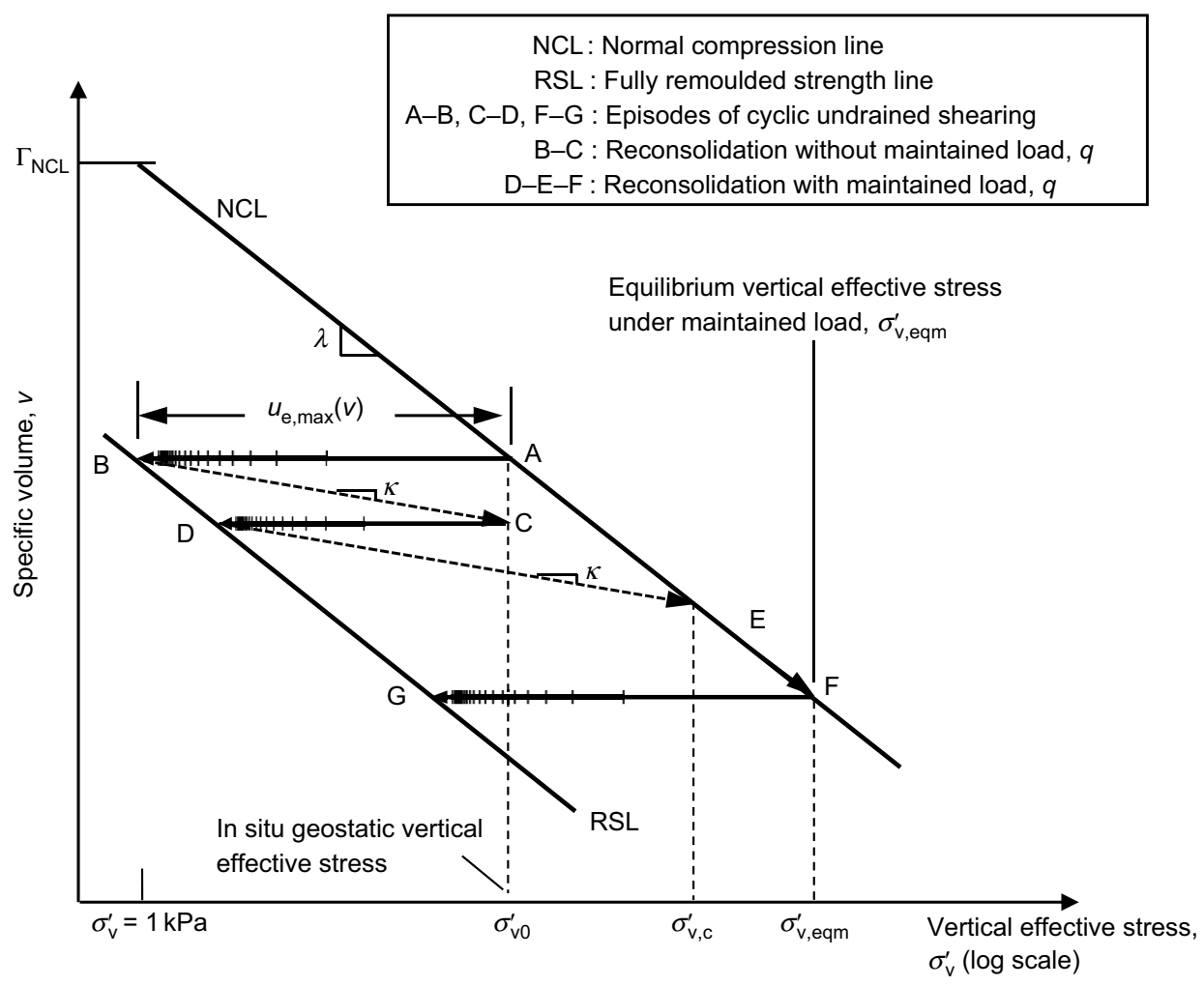

Fig. 7. Changes in vertical effective stress and specific volume during undrained cyclic loading, reconsolidation and maintained load 
where $\sigma_{\mathrm{v}}^{\prime}(\hat{z})=\sigma_{\mathrm{v} 0}^{\prime}(\hat{z})+q I_{\sigma}(\hat{z})-u_{\mathrm{e}}(\hat{z})$. The lumped strength parameter was defined as a variable with number of cycles by Hodder et al. (2013), to capture effects from overconsolidation, destructuration or changes in $K_{0}$ through shearing events. A similar approach is used in the present framework, but with $\Phi$ varying with the cumulative shear strain, and is taken to decay exponentially from a peak value $k_{\Phi} \Phi_{\text {steady }}$ to a steady value, $\Phi_{\text {steady }}$

$$
\Phi(\hat{z})=k_{\Phi}(\hat{z}) \Phi_{\text {steady }}-\left[k_{\Phi}(\hat{z})-1\right]\left(1-\mathrm{e}^{-3 \varepsilon(\hat{z}) / \varepsilon_{95, \Phi}}\right) \Phi_{\text {steady }}
$$

where $k_{\Phi}(\hat{z})$ is a strength parameter multiplier linked to the OCR and a peak strength parameter, $b$, expressed as $k_{\Phi}(\hat{z})=\operatorname{OCR}(\hat{z})^{b}$ (Schofield \& Wroth, 1968; Muir Wood, 1990). $\varepsilon_{95, \Phi}$ is the cumulative (absolute) shear strain required to cause a $95 \%$ reduction from the peak value to the steady value, $\Phi_{\text {steady }}$ (since $\mathrm{e}^{-3} \approx 0 \cdot 05$ ). Combining the lumped strength parameter and a measured cyclic soil sensitivity, $S_{\mathrm{t}, \mathrm{cyc}}$, allows the range of soil undrained shear strength from intact to fully remoulded conditions to be modelled. The fully remoulded strength is linked to the fully remoulded stress, $\sigma_{\mathrm{v}, \mathrm{RSL}}^{\prime}$, at the RSL, and is given by Hodder et al. (2013) as

$$
\begin{aligned}
& \sigma_{\mathrm{v}, \mathrm{RSL}}^{\prime}(\hat{z})=\left[\frac{s_{\mathrm{u}}}{\sigma_{\mathrm{v} 0}^{\prime}}\right]_{\mathrm{NC}} \frac{\sigma_{\mathrm{v} 0}^{\prime}(\hat{z})}{\Phi_{\text {steady }} S_{\mathrm{t}, \mathrm{cyc}}} \\
& \exp \left(\frac{\Lambda\left\{\Gamma_{\mathrm{NCL}}-v_{\text {initial }}(\hat{z})-\lambda \ln \left[\sigma_{\mathrm{v} 0}^{\prime}(\hat{z})\right]\right\}}{\lambda-\kappa}\right)
\end{aligned}
$$

where $\left[s_{\mathrm{u}} / \sigma_{\mathrm{v} 0}^{\prime}\right]_{\mathrm{NC}}$ is the normally consolidated undrained strength ratio; $\Lambda$ is the plastic volumetric strain ratio; $\Gamma_{\mathrm{NCL}}$ is the specific volume at $\sigma_{\mathrm{v}}^{\prime}=1 \mathrm{kPa}$ on the NCL; and $v_{\text {initial }}$ is the initial specific volume.

Variation in soil strength due to a maintained load. During consolidation, dissipation of the excess pore pressures leads to a regain in soil strength. For the subsequent undrained shearing, the consolidated soil strength, $s_{\mathrm{u}, \mathrm{c}}$, can be calculated by equation (10) considering the progressive build-up of excess pore pressure and the reduction in vertical effective stress using the new maximum excess pore pressure associated with the current specific volume (see Fig. 7).

Average soil strength and mobilisation response. The average undrained shear strength at the current location of the object, $s_{\mathrm{u}, \mathrm{av}}$, is obtained by integrating the weighted undrained shear strength within the strength influence zone defined in Fig. 5(h), through a strength influence function, $v_{\mathrm{s}}(\hat{z})$.

$$
s_{\mathrm{u}, \mathrm{av}}=\int_{\hat{z}_{\mathrm{m}}-\alpha}^{\hat{\mathrm{m}}_{\mathrm{m}}+\alpha} s_{\mathrm{u}}(\hat{z}) v_{\mathrm{s}}(\hat{z}) \mathrm{d} z
$$

When the object changes direction, mobilisation of the soil strength is captured by a non-linear strength-displacement model. The model provides a high tangent stiffness as motion begins in a new direction, and the tangent stiffness decays with displacement so the mobilised soil strength, $s_{\mathrm{u}, \mathrm{mob}}$, asymptotically approaches the (spatially averaged) available soil strength, $s_{\mathrm{u}, \mathrm{av}}$. Many expressions have been used to capture the non-linear soil stiffness for soil (e.g. Janbu, 1985; Puzrin \& Burland, 1998; Atkinson, 2000). In this paper, the normalised mobilised soil strength, $\left(s_{\mathrm{u}, \mathrm{mob}} / s_{\mathrm{u}, \mathrm{av}}\right)$, rises with displacement at a tangent stiffness, $K$, expressed as

$$
\delta\left(\frac{s_{\mathrm{u}, \mathrm{mob}}}{s_{\mathrm{u}, \mathrm{av}}}\right)=\delta(\hat{z}) K
$$

in which the effective tangent stiffness, $K$, is gradually reduced according to the proportion of the change in mobilised strength that has occurred (including any unloading). After any reversal, the potential change is defined as $\left(\left|\Delta s_{\mathrm{u}, \max }\right| s_{\mathrm{u}, \mathrm{av}}\right)$ and lies in the range $0-2$, and the current change is given by $\left(\left|\Delta s_{\mathrm{u}, \mathrm{mob}}\right| s_{\mathrm{u}, \mathrm{av}}\right)$ as shown in Fig. 8 . The tangent stiffness is then given as

$$
K=\left\{1-\left[\frac{\Delta\left(s_{\mathrm{u}, \text { mob }} / s_{\mathrm{u}, \mathrm{av}}\right)}{\Delta\left(s_{\mathrm{u}, \max } / s_{\mathrm{u}, \mathrm{av}}\right)}\right]^{\zeta}\right\} K_{\text {max }}
$$

where $\zeta$ is the power law parameter to account for the non-linear change in tangent stiffness. $K_{\max }$ is the maximum tangent stiffness that is adopted since the last reversal in penetration or extraction. To accurately capture changes in initial stiffness during small-amplitude cycles, $K_{\max }$ can be

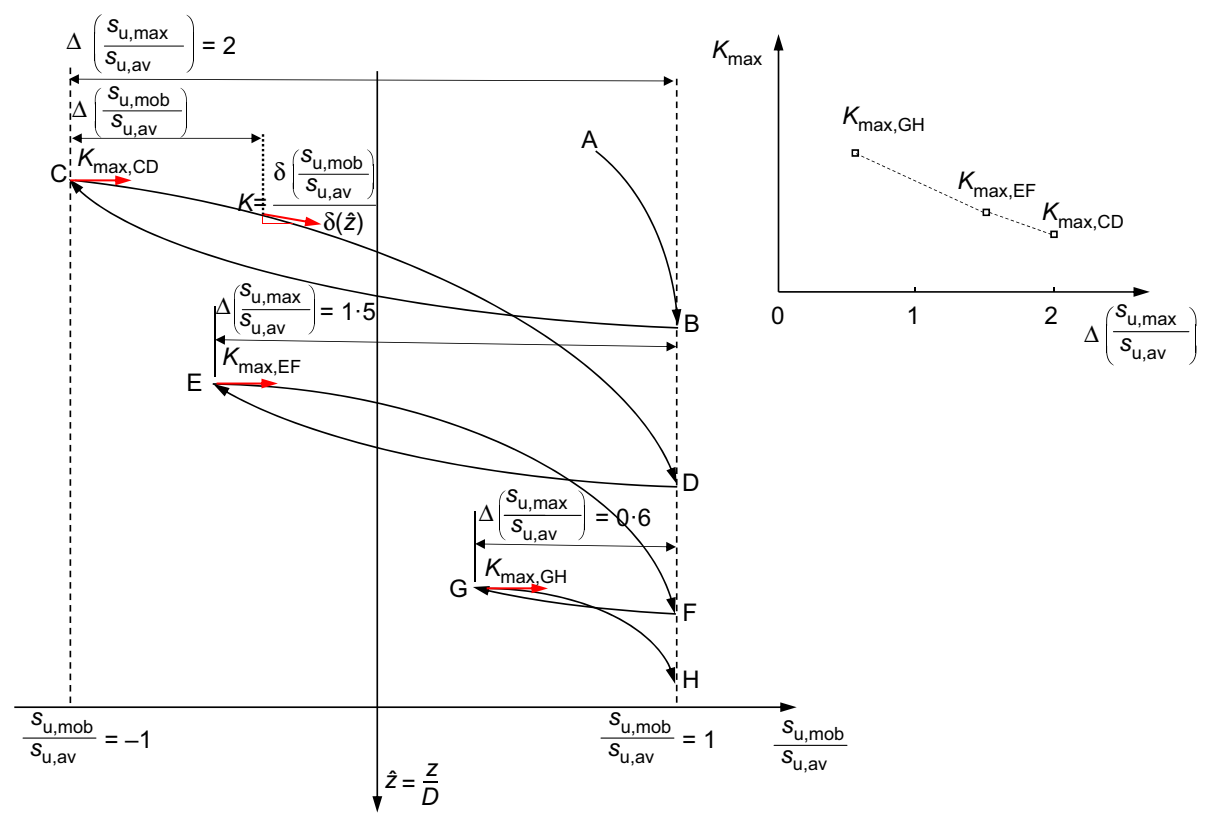

Fig. 8. Mobilisation of soil strength under complex motion 
assigned a variation with $\left(\left|\Delta s_{\mathrm{u}, \text { max }}\right| s_{\mathrm{u}, \text { av }}\right)$, as shown in Fig. 8, but this is not explored in the present paper.

\section{Types of analysis (operations)}

In order to combine effects of maintained load, remoulding and reconsolidation, the new framework consists of two types of step - displacement-controlled and load-controlled. For a displacement-controlled step, an incremental displacement of the penetrating object results in a rise in excess pore pressure due to the corresponding incremental shear strains, and therefore causes degradation of soil strength. For the load-controlled analysis, with an input load (or pressure), the displacement of the object is calculated and, dependent on the resulting displacement, the soil strength profile is updated. An iteration is involved where the soil strength is degraded owing to a given displacement step, and the penetration depth is updated until vertical equilibrium is reached at greater depth. The two operations enable simulation of cyclic penetrometer tests and practical field operations such as jack-up spudcan installation. A flow chart showing the procedures of the new framework is presented in Fig. 9.

\section{SIMULATION USING THE NEW FRAMEWORK}

Benchmarking analysis against cyclic T-bar penetration test Framework parameters. A benchmarking analysis against the cyclic T-bar test described earlier was carried out using the appropriate framework parameters presented in Table 2.

The critical state parameters are determined from laboratory element tests (data from Stewart (1992)), with the normally consolidated undrained strength ratio, $\left[s_{\mathrm{u}} / \sigma_{\mathrm{v} 0}^{\prime}\right]_{\mathrm{NC}}$, quantified from the initial penetration phase of the T-bar tests. For a lightly overconsolidated clay, the initial specific volume of the soil is calculated based on the OCR and in situ geostatic vertical effective stress, $\sigma_{\mathrm{v} 0}^{\prime}$, following a critical state context (Schofield \& Wroth, 1968; Muir Wood, 1990), given by

$$
v_{\text {initial }}(\hat{z})=\Gamma_{\mathrm{NCL}}-\lambda \ln \left[\mathrm{OCR}(\hat{z}) \sigma_{\mathrm{v} 0}^{\prime}(\hat{z})\right]+\kappa \ln [\mathrm{OCR}(\hat{z})]
$$

The lumped strength parameter, $\Phi_{\text {steady, }}$ is obtained by predicting the best-fitted fully remoulded shear strength after each episode of cyclic loading. A value of $\Phi_{\text {steady }}=0.6$ is selected to achieve good agreement with the measured fully remoulded strength for all three episodes. However, to capture effects from overconsolidation, destructuration or changes in $K_{0}$ through shearing events, $\Phi$ is taken to decay exponentially from a peak value, $k_{\Phi} \Phi_{\text {steady }}$ to $\Phi_{\text {steady }}$, by way of equation (11).

The parameters of the excess pore pressure model control the rate of excess pore pressure generation, and therefore influence the degradation of soil strength during cyclic penetration shearing. The best-fit values of $p=3 \cdot 15$, $\varepsilon_{99}=100, b=0.65$ and $\varepsilon_{95, \Phi}=28$ are determined by fitting the initial and cyclic undrained shear strength profiles for the

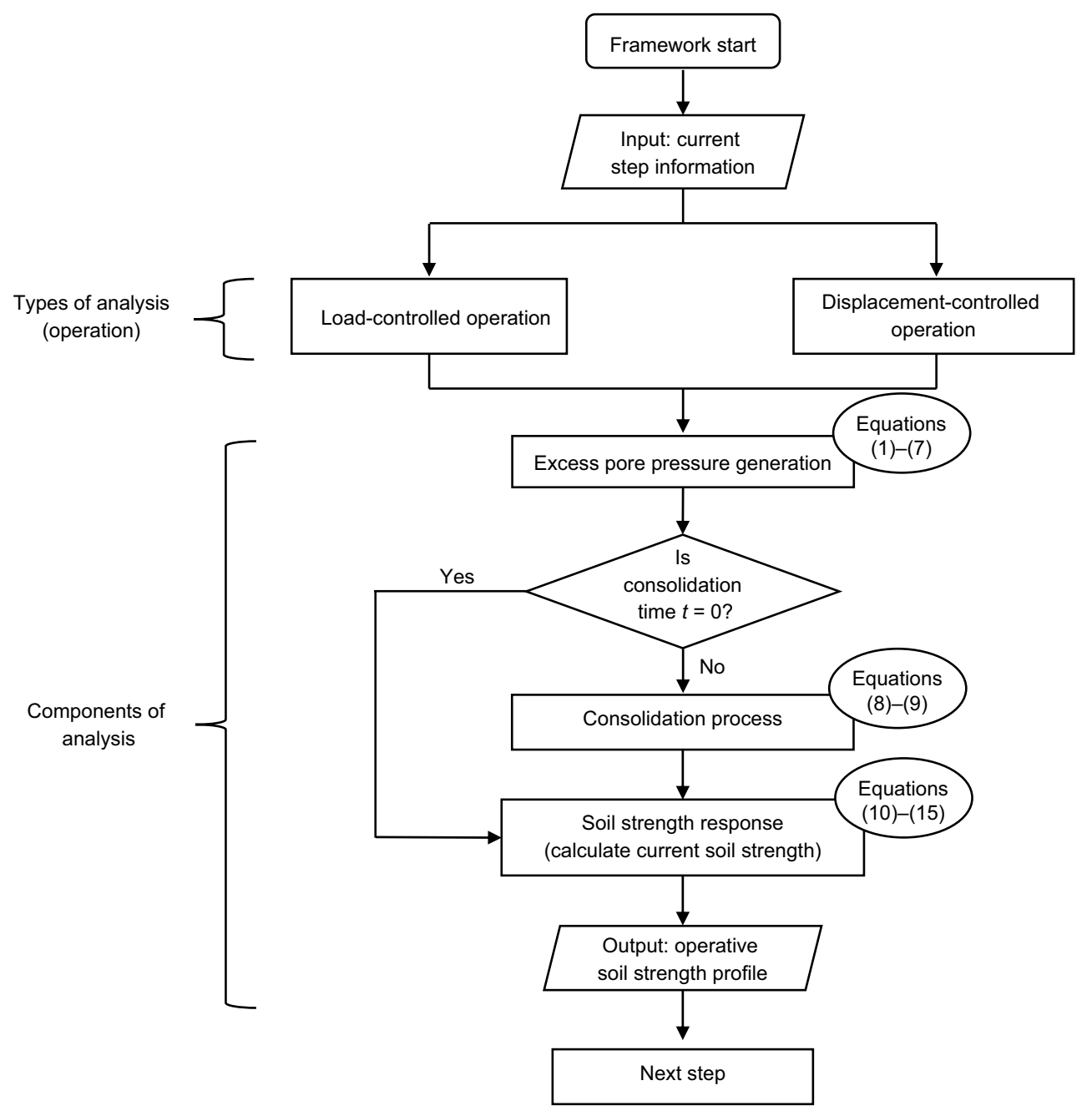

Fig. 9. Framework procedure 
Table 2. Summary of framework parameters (cyclic T-bar penetration test)

\begin{tabular}{|c|c|c|c|c|}
\hline Framework component & Parameters & Dimensions & Description & Value \\
\hline Geometry & $D$ & & Diameter of object & $0 \cdot 25 \mathrm{~m}$ \\
\hline \multirow{5}{*}{ Soil characteristics } & & $\left(\mathrm{F} / \mathrm{L}^{3}\right)$ & Effective unit weight & $5.5 \mathrm{kN} / \mathrm{m}^{3}$ \\
\hline & OCR & & Overconsolidation ratio & After Hodder $e t$ al. \\
\hline & & & & (2013) \\
\hline & & & Specific gravity & $2 \cdot 6$ \\
\hline & $S_{\mathrm{t}, \mathrm{cyc}}$ & & Cyclic soil sensitivity & $2 \cdot 55$ \\
\hline \multirow[t]{5}{*}{ Critical state model } & & & Compression index & $0 \cdot 205$ \\
\hline & & & Swelling index & $0 \cdot 044$ \\
\hline & & & Plastic volumetric strain ratio & $0 \cdot 6$ \\
\hline & $\left(s_{\mathrm{u}} / \sigma_{\mathrm{v} 0}^{\prime}\right)_{\mathrm{NC}}$ & & $\begin{array}{l}\text { Normally consolidated undrained strength } \\
\text { ratio }\end{array}$ & $0 \cdot 2$ \\
\hline & $\Gamma_{\mathrm{NCL}}$ & & Specific volume, $v$, at $\sigma_{\mathrm{v}}^{\prime}=1 \mathrm{kPa}$ on NCL & $3 \cdot 251$ \\
\hline \multirow[t]{3}{*}{ Excess pore pressure generation } & $\varepsilon_{99}$ & & Cumulative shear strain parameter & 100 \\
\hline & & & Shear strain rate parameter & $3 \cdot 15$ \\
\hline & & & Strain influence zone extent & $1 D$ \\
\hline \multirow[t]{3}{*}{ Consolidation process } & & & Load sharing factor & 0 \\
\hline & & & Non-dimensional time parameter & $0 \cdot 09$ \\
\hline & & & Embedment level parameter & $1 \cdot 05$ \\
\hline \multirow[t]{6}{*}{$\begin{array}{l}\text { General soil strength and stiffness } \\
\text { response }\end{array}$} & $\Phi_{\text {steady }}$ & & $\begin{array}{l}\text { Strength parameter at steady, remoulded } \\
\text { conditions }\end{array}$ & \\
\hline & $b$ & & Peak strength parameter & $0 \cdot 65$ \\
\hline & $\varepsilon_{95, \Phi}$ & & Peak strength ductility & 28 \\
\hline & & & Strength influence zone extent & $1 D$ \\
\hline & $K_{\max }$ & & Maximum tangent stiffness & $32 \cdot 5$ \\
\hline & & & $\begin{array}{l}\text { Power law parameter for strength } \\
\text { mobilisation }\end{array}$ & $0 \cdot 32$ \\
\hline
\end{tabular}
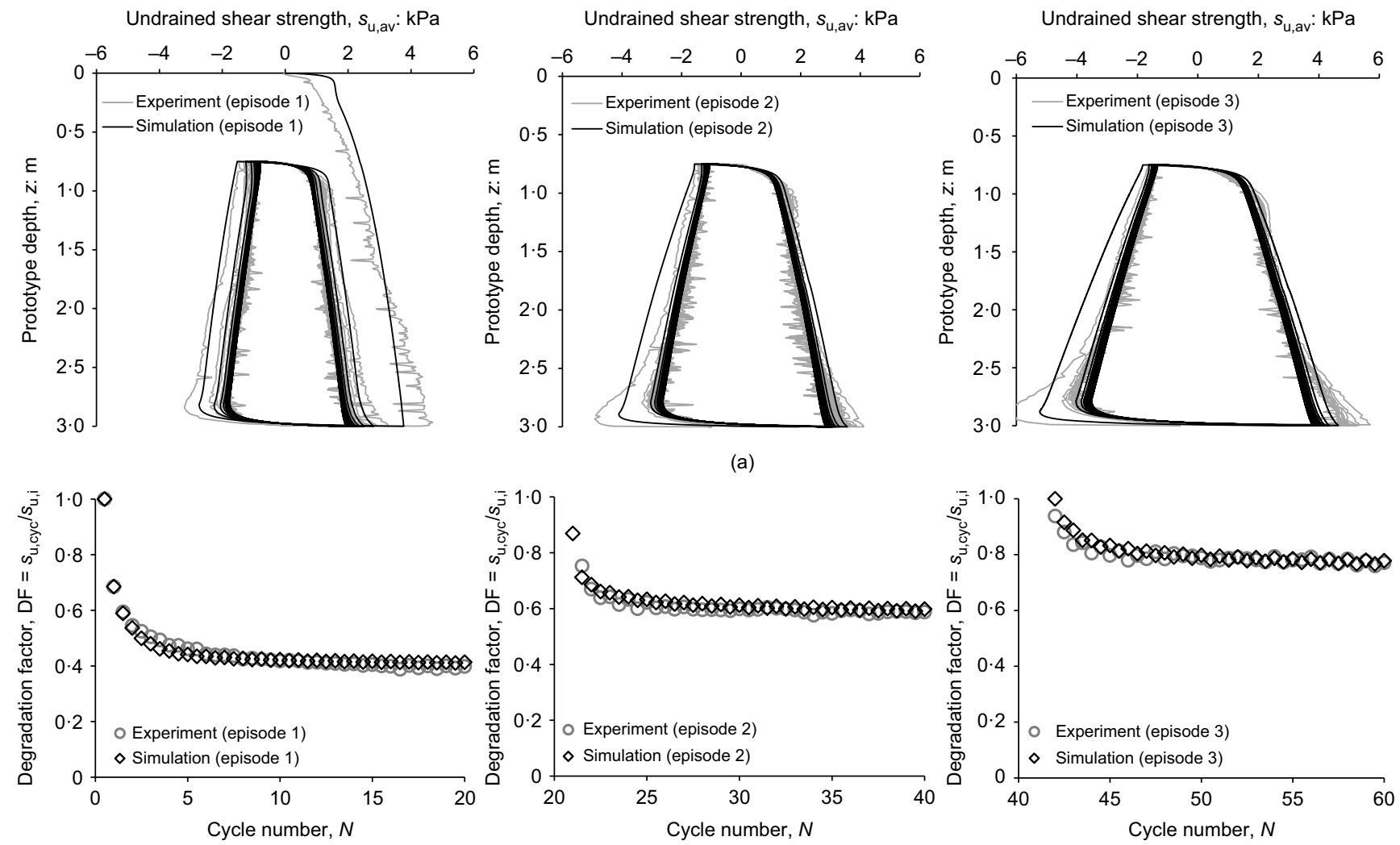

(b)

Fig. 10. Comparison of experimental and predicted undrained shear strength during three cyclic episodes: (a) full undrained shear strength profiles; (b) degradation factor, $\mathrm{DF}=s_{\mathrm{u}, \mathrm{cyc}} / s_{\mathrm{u}, \mathrm{i}}$, at mid-depth of cyclic range $(z=1.75 \mathrm{~m})$

first cyclic episode. For the consolidation, a simple hyperbolic equation with $T_{50}=0.09$ and $m=1.05$ (see Chatterjee et al. (2013)) is adopted.

A value of $\beta=1$ is used to defined the shear strain influence zone, and $\alpha=1$ is used to define the strength influence zone used in the calculation of the average undrained shear strength, $s_{\mathrm{u}, \text { av }}$ (Einav \& Randolph, 2005; Hodder et al., 2013). For a strength-displacement model, values of $K_{\max }=32.5$ and $\zeta=0 \cdot 32$ provide a good match with the measured mobilisation of soil strength during the first cyclic episode. 
Results and discussion. Figure 10 shows a very good correlation between the undrained shear strength measured in the centrifuge sample by a cyclic T-bar test and estimated by the framework. A reconsolidation period of 1 year (at prototype scale) between each episode is equivalent to a normalised time of $T \sim 32$ with a coefficient of consolidation, $c_{\mathrm{v}}=2 \mathrm{~m}^{2} /$ year. Based on the hyperbolic dissipation, the degree of dissipation is $U \sim 0.99$, meaning that $99 \%$ of the initial excess pore pressure has dissipated during the pause period. After the reconsolidation between

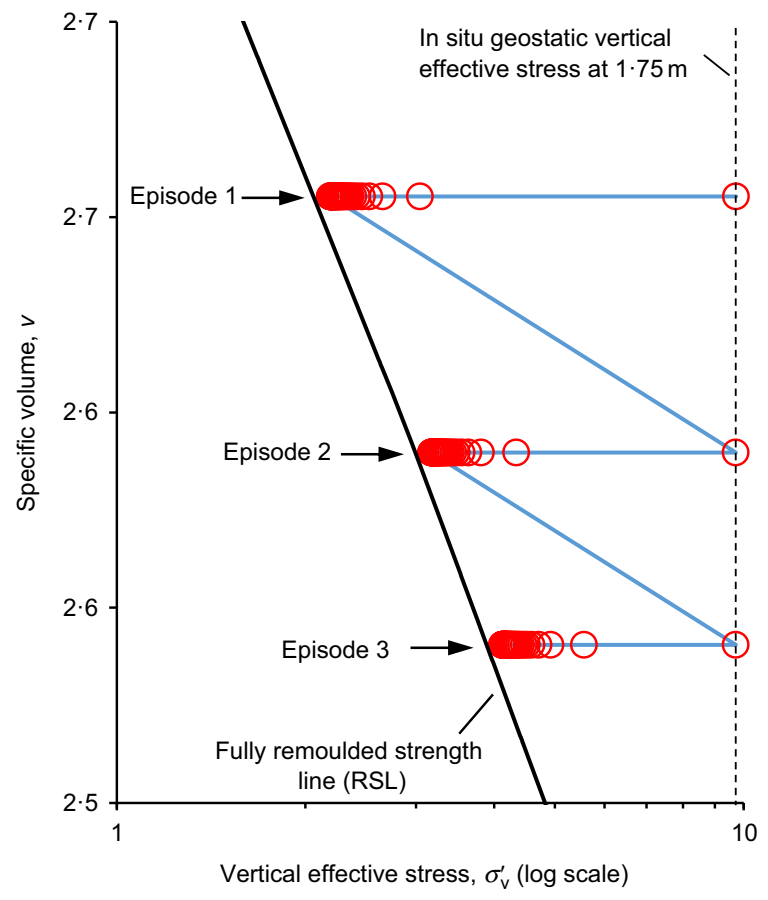

Fig. 11. Calculated variation in effective stress state during three cyclic episodes (at $z=1.75 \mathrm{~m}$ ) cyclic episodes 2 and 3, a significant increase in soil strength is also well captured by the framework simulation.

In Fig. 10(b), the predicted variation in soil strength at a depth, $z=1.75 \mathrm{~m}$ is presented against measured test data by a degradation factor, $\mathrm{DF}=s_{\mathrm{u}, \mathrm{cyc}} / s_{\mathrm{u}, \mathrm{i}}$ in which $s_{\mathrm{u}, \mathrm{cyc}}$ is the soil strength from the cyclic phases. DF gradually decreases to a steady value in each cyclic episode, but after the reconsolidation, the regain in soil strength is well captured by the framework.

Figure 11 shows the estimated variation in stress state at a depth of $1.75 \mathrm{~m}$. During cyclic undrained shearing, the cumulative excess pore pressure causes a gradual reduction in effective stress and, through reconsolidation, the excess pore pressure dissipation leads to a rise in effective stress, a decrease in specific volume and a higher corresponding remoulded stress. These variations in stress state cause significant increases in cyclic shear strength and fully remoulded strength.

These simulations demonstrate that the framework can replicate the soil strength degradation owing to continuous cycles of undrained shearing, and the regain in soil strength following the reconsolidation period.

Benchmarking analysis against spudcan penetration test Framework parameters. The second benchmarking analysis was performed against spudcan penetration tests that consider the effect of varying levels of maintained load and consolidation time. The details of the experimental programme were described earlier, and the framework parameters and an overview of the test cases are summarised in Tables 3 and 4, respectively.

As these experiments were also conducted in kaolin clay, the critical state soil parameters are identical to those used in the analysis of the Hodder et al. (2009) T-bar tests. The exception is the normally consolidated undrained strength ratio, $\left[s_{\mathrm{u}} / \sigma_{\mathrm{v} 0}^{\prime}\right]_{\mathrm{NC}}$, which was quantified from the T-bar tests conducted in the samples used for the spudcan tests (Bienen \& Cassidy, 2013) using the same $N_{\mathrm{c}}=10 \cdot 5$ (Martin \& Randolph, 2006) as adopted for the T-bar simulations. A reference profile of normalised penetration

Table 3. Summary of framework parameters (spudcan penetration test)

\begin{tabular}{|c|c|c|c|c|}
\hline Framework component & Parameters & Dimensions & Description & Value \\
\hline Geometry & $D$ & (L) & Diameter of object & $12 \mathrm{~m}$ \\
\hline \multirow[t]{4}{*}{ Soil characteristics } & & $\left(\mathrm{F} / \mathrm{L}^{3}\right)$ & Effective unit weight & $7 \mathrm{kN} / \mathrm{m}^{3}$ \\
\hline & OCR & & Overconsolidation ratio & \\
\hline & $G_{\mathrm{s}}$ & & Specific gravity & \\
\hline & $S_{\mathrm{tcyc}}$ & & Cyclic soil sensitivity & $2 \cdot 5$ \\
\hline \multirow[t]{5}{*}{ Critical state model } & & & Compression index & $0 \cdot 205$ \\
\hline & & & Swelling index & $0 \cdot 044$ \\
\hline & & & Plastic volumetric strain ratio & $0 \cdot 6$ \\
\hline & $\left(s_{\mathrm{u}} / \sigma_{\mathrm{v} 0}^{\prime}\right)_{\mathrm{NC}}$ & & Normally consolidated undrained strength ratio & $0 \cdot 17$ \\
\hline & $\Gamma_{\mathrm{NCL}}$ & & Specific volume, $v$, at $\sigma_{\mathrm{v}}^{\prime}=1 \mathrm{kPa}$ on NCL & $3 \cdot 251$ \\
\hline \multirow[t]{3}{*}{ Excess pore pressure generation } & & & Cumulative shear strain parameter & 100 \\
\hline & & & Shear strain rate parameter & $2 \cdot 6$ \\
\hline & & & Strain influence zone extent & $0 \cdot 5 D$ \\
\hline \multirow{3}{*}{ Consolidation process } & & & Load sharing factor & $0 \cdot 1$ \\
\hline & & & Non-dimensional time parameter & $0 \cdot 05$ \\
\hline & & & Embedment level parameter & $0 \cdot 9$ \\
\hline \multirow{6}{*}{$\begin{array}{l}\text { General soil strength and stiffness } \\
\text { response }\end{array}$} & $\Phi_{\text {steady }}$ & & $\begin{array}{l}\text { Strength parameter at steady, remoulded } \\
\text { conditions }\end{array}$ & \\
\hline & $b$ & & Peak strength parameter & $0 \cdot 65$ \\
\hline & $\varepsilon_{95, \Phi}$ & & Peak strength ductility & 28 \\
\hline & $\alpha$ & & Strength influence zone extent & $0 \cdot 5 D$ \\
\hline & $K_{\max }$ & & Maximum tangent stiffness & 480 \\
\hline & & & Power law parameter for strength mobilisation & $0 \cdot 2$ \\
\hline
\end{tabular}


Table 4. Overview of simulation cases (spudcan penetration tests)

\begin{tabular}{|c|c|c|c|c|}
\hline Experiment (Bienen \& Cassidy, 2013): - & $\begin{array}{c}\text { Target depth } \\
\text { with } D=12 \mathrm{~m}: \mathrm{m}\end{array}$ & Consolidation time: years & $T=\left(c_{\mathrm{v}} t\right) / D$ & Maintained load: $\mathrm{kPa}$ \\
\hline $\mathrm{T} 1$ & - & - & - & Reference test \\
\hline T9 & $0 \cdot 5 D$ & $0 \cdot 5$ & $0 \cdot 01$ & $55 \cdot 3$ \\
\hline $\mathrm{T} 11$ & $0 \cdot 5 D$ & 1 & $0 \cdot 019$ & $52 \cdot 5$ \\
\hline $\mathrm{T} 18$ & $0 \cdot 5 \mathrm{D}$ & 18 & $0 \cdot 343$ & $62 \cdot 2$ \\
\hline $\mathrm{T} 12$ & $1 \cdot 0 \mathrm{D}$ & $0 \cdot 25$ & $0 \cdot 006$ & $144 \cdot 6$ \\
\hline $\mathrm{T} 3$ & $1 \cdot 0 D$ & $0 \cdot 5$ & $0 \cdot 013$ & $126 \cdot 6$ \\
\hline $\mathrm{T} 14$ & $1 \cdot 0 D$ & 1 & $0 \cdot 024$ & $145 \cdot 2$ \\
\hline $\mathrm{T} 5$ & $1 \cdot 0 D$ & 18 & $0 \cdot 457$ & $131 \cdot 9$ \\
\hline $\mathrm{T} 7$ & $1 \cdot 5 D$ & $0 \cdot 25$ & $0 \cdot 007$ & $244 \cdot 3$ \\
\hline T6 & $1 \cdot 5 D$ & $0 \cdot 5$ & $0 \cdot 015$ & $233 \cdot 7$ \\
\hline T8 & $1 \cdot 5 D$ & 18 & $0 \cdot 52$ & 226 \\
\hline
\end{tabular}

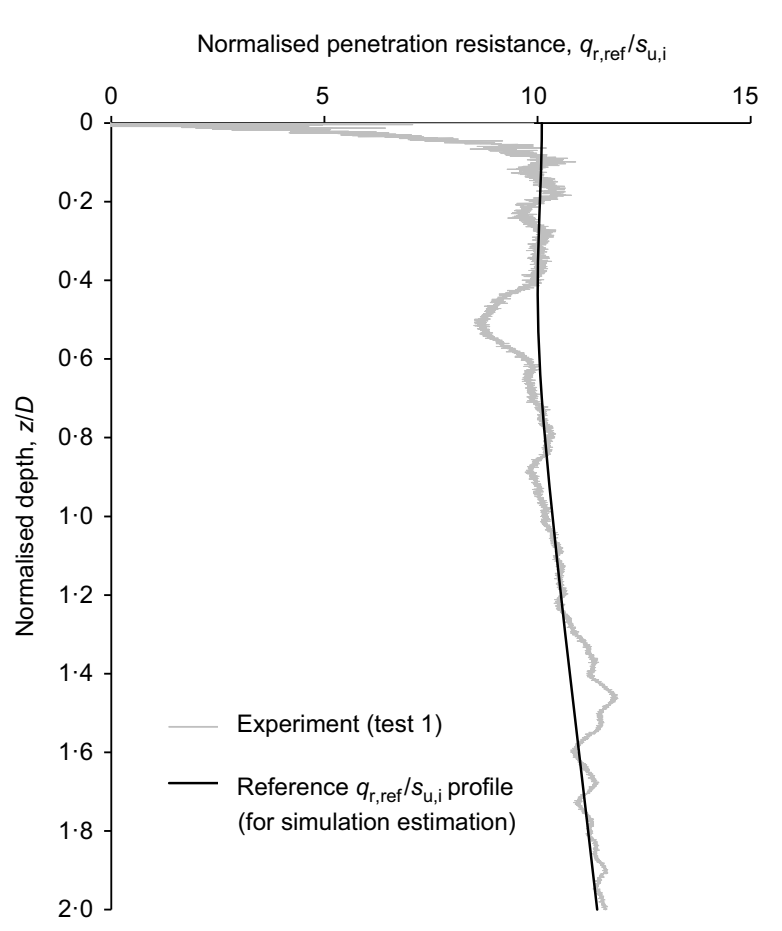

Fig. 12. Measured and fitted profiles of normalised penetration resistance for the reference spudcan case

resistance (based on test 1 , which had no consolidation period), $q_{\mathrm{r}, \mathrm{ref}} / s_{\mathrm{u}, \mathrm{i}}$, is shown in Fig. 12 , and is seen to be well described by $q_{\mathrm{r}, \mathrm{ref}} / s_{\mathrm{u}, \mathrm{i}}=10 \cdot 1$ for $z / D \leq 0 \cdot 7$, and by $q_{\mathrm{r}, \mathrm{ref}} / s_{\mathrm{u}, \mathrm{i}}=10 \cdot 1+1 z$ for $z / D>0 \cdot 7$.

Owing to the absence of cyclic T-bar data for this study, the lumped strength parameter is taken as $\Phi_{\text {steady }}=0.6$, identical to that used in the first benchmarking analysis for the kaolin clay. The excess pore pressure model parameters were selected as $p=2.6$ and $\varepsilon_{99}=100$ by minimising the residuals between the measured and predicted initial undrained shear strengths. Values of $b$ and $\varepsilon_{95, \Phi}$ were maintained from the parameter set for the simulation of the Hodder et al. (2009) T-bar tests, although they are not invoked by the framework in this case, as the soil is normally consolidated.

Values of $\beta=0.5$ and $\alpha=0.5$ are selected to define the shear strain influence zone and the strength influence zone, respectively, as informed by clay failure mechanisms during spudcan penetration (Hossain \& Randolph, 2009). As the spudcan tests did not involve penetration and extraction stages, $K_{\max }$ and $\zeta$ were selected by noting the values that best captured the measured resistance-displacement response during spudcan repenetration after a short consolidation period $(0 \cdot 25$ years $) . K_{\max }=480$ and $\zeta=0 \cdot 2$ provided the best agreement.

The coefficient of consolidation, $c_{\mathrm{v}}$, is taken as $2.6 \mathrm{~m}^{2} /$ year at $0.5 \mathrm{D}$ depth, $3.5 \mathrm{~m}^{2} /$ year at $1.0 \mathrm{D}$ depth and $4.0 \mathrm{~m}^{2} /$ year at $1.5 D$ depth after Bienen \& Cassidy (2013), with a linear variation in between. The consolidation parameters, $T_{50}=0.05$ and $m=0.95$, best described the measured dissipation response reported in Bienen \& Cassidy (2013) and were consequently adopted here. The maintained load is assumed to be transmitted $90 \%$ by way of compression by specifying $\eta=0 \cdot 1$. An extension study exploring this assumption is described later, varying $\eta$ from 0 to $0 \cdot 9$.

Results and discussion. Changes in excess pore pressure and vertical effective stress during consolidation. Figure 13 presents changes in excess pore pressure (Fig. 13(a)) and vertical effective stress (Fig. 13(b)) from the simulation analyses at the consolidation depth of $z / D \sim 1$ for a range of consolidation periods from $0 \cdot 25$ to 18 years. The in situ geostatic effective stress was reduced initially by the excess pore pressure due to shearing from the initial penetration stage. An additional excess pore pressure was generated as the maintained load was applied, and negative pore pressure was developed above the spudcan scaled by a negative pore pressure factor of $\eta=0 \cdot 1$.

During the consolidation, the dissipation of excess pore pressure without maintained load leads to an increase in vertical effective stress towards the in situ value. Meanwhile the dissipation of excess pore pressure due to a maintained load results in an additional increase in vertical effective stress towards a new equilibrium value (Fig. 13(b)). The contribution of dissipated excess pore pressure (Fig. 13(a)) causes a reduction in specific volume and gain in soil strength, which are enhanced by the maintained load.

Above the spudcan, the magnitude of negative pore pressure neutralises the excess pore pressure generated by the initial penetration stage as the maintained load is applied. This reduces the change in vertical effective stress, and the resulting soil densification during consolidation.

Improved penetration resistance. The improved normalised penetration resistance after consolidation is given by

$$
\frac{q_{\mathrm{r}}}{s_{\mathrm{u}, \mathrm{i}}}(\hat{z})=\left[\frac{q_{\mathrm{r}, \mathrm{ref}}}{s_{\mathrm{u}, \mathrm{i}}}(\hat{z})\right] \frac{s_{\mathrm{u}, \mathrm{c}}(\hat{z})}{s_{\mathrm{u}, \mathrm{i}}(\hat{z})}
$$

where $s_{\mathrm{u}, \mathrm{c}}$ is the consolidated soil strength predicted by framework analysis. 


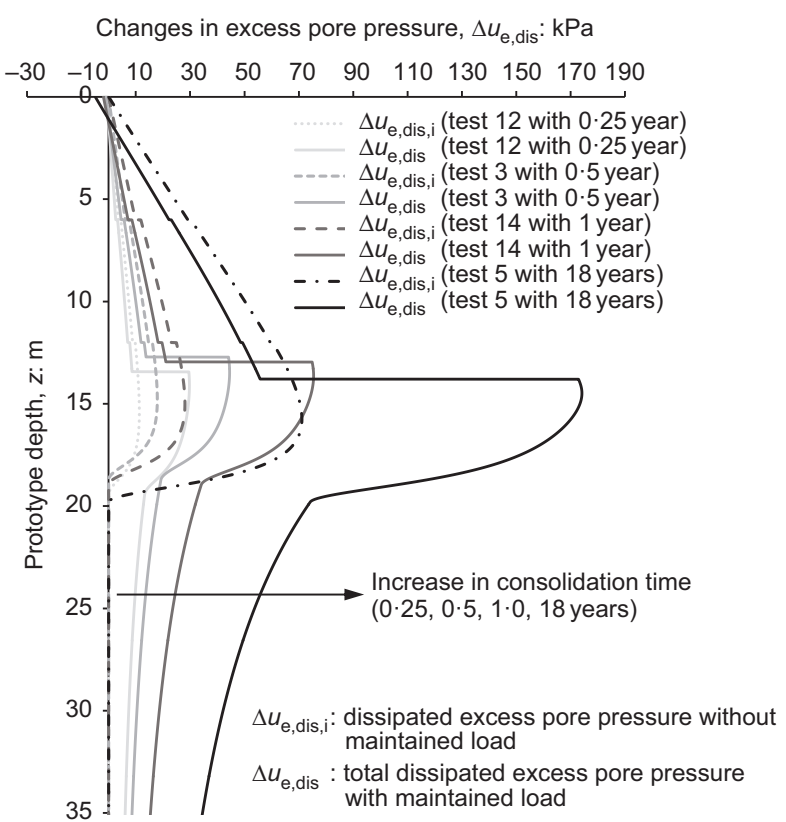

(a)

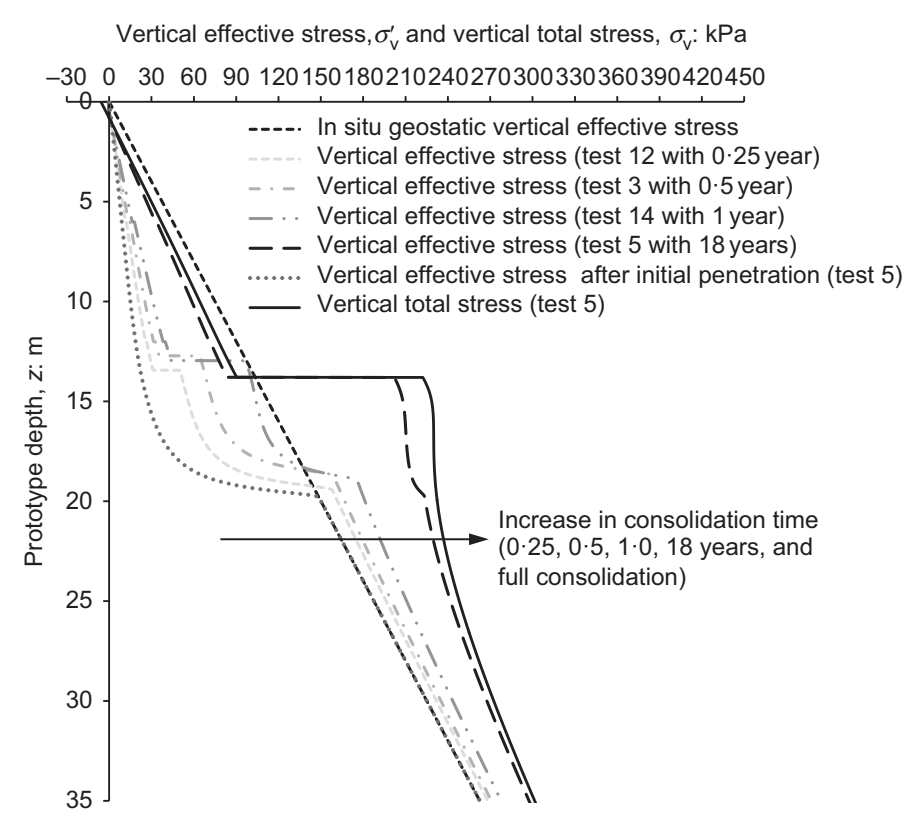

(b)

Fig. 13. Variation in: (a) excess pore pressure and (b) vertical effective stress during a range of consolidation periods from $0 \cdot 25$ years to 18 years at a depth of $\sim 1 D$

Figure 14 compares the predicted and measured profiles of $q_{\mathrm{f}} / s_{\mathrm{u}, \mathrm{i}}(\hat{z})$ for all 11 test cases, with consolidation periods from 0.25 year to 18 years, and consolidation depths at $0.5 \mathrm{D}, 1.0 \mathrm{D}$ and $1.5 \mathrm{D}$. The simulations show remarkable agreement with the experimental data, for both the peak in resistance and also the improved zone beneath (defined in Fig. 15).

Improved peak resistance: the effect of the consolidation duration and maintained load on the post-consolidation resistance can be quantified by a peak resistance ratio, $q_{\mathrm{r}, \text { peak }} / q_{\mathrm{r} \text {,ref }}$, where $q_{\mathrm{r} \text {,ref }}$ is the resistance at the same depth for the case without a consolidation period. Fig. 16 compares the peak resistance ratio estimated by the framework and measured in the centrifuge tests. The predicted peak resistance varies with consolidation time, reflecting the different levels of excess pore pressure dissipation. Overall, the framework provides a very reasonable estimate of the peak resistance measured in the centrifuge tests.

The predicted peak in resistance is affected by the assumption made on the load sharing above and below the spudcan, from $\eta=0$ (no 'hanging' effect from the overlying soil) to $\eta=0.9$ (almost fully 'hanging' from the overlying soil). Additional simulations were conducted using different values of $\eta$ at the target depth of $z \sim 1.0 D$ with a maintained load, $q=131.9 \mathrm{kPa}$. The results are expressed as the peak resistance ratio, $q_{\mathrm{r}, \text { peak }} / q_{\mathrm{r}, \mathrm{ref}}$, and plotted against dimensionless time, $T$ in Fig. 17. For each $\eta$, the estimated $q_{\mathrm{r} \text {,peak }} / q_{\mathrm{r} \text {,ref }}$ increases with consolidation time (except the analysis with $\eta=0.9$ ). This shows that the rise in soil strength from compression outweighs the loss in strength from swelling, which is consistent with the compression paths reaching the NCL, giving a greater reduction in specific volume and therefore strength gain. For all analyses, a low value of $\eta$ results in a high consolidated peak resistance after a given consolidation period, and vice versa.

Improved zone: following mobilisation of the postconsolidation peak in resistance, the spudcan pushes through an improved zone as defined in Fig. 15. Fig. 14 also compares the predicted and measured extent and size of this improved zone. The extent of the improved zone depends on the magnitude of the maintained load and the consolidation period. This is captured by the framework, since the zone of excess pore pressure is increased by the level of maintained load. The results indicate excellent agreement at deep consolidation depth $(z / D \sim 1$ and 1.5) and a slight underestimation for the shallower cases.

\section{CONCLUSIONS}

This paper sets out an analytical framework to predict changing penetration resistance caused by variations in soil strength caused by maintained load, remoulding and reconsolidation, with sufficient generality for complex histories of load and displacement to be replicated. The framework idealises the soil domain by way of a onedimensional vertical discretisation, using critical state concepts for the generation and dissipation of pore pressure and the resulting changes in soil strength.

A benchmarking analysis against a T-bar test with three cyclic penetration episodes was performed. The framework prediction is in good agreement with experimental data for each cyclic episode. The framework reproduces the soil degradation during the cyclic penetration, along with the regain in soil strength owing to reconsolidation. This benchmarking analysis, therefore, validates that the analytical components in the framework can capture the changing soil strength due to cyclic remoulding and reconsolidation.

In the second benchmarking analysis, the framework simulates a set of spudcan footing penetration tests with a series of consolidation periods. The simulations reproduce well the enhanced penetration resistance due to increasing soil strength and the improved zone following the subsequent penetration process. This analysis reveals that the framework can provide a simple means to assess soil-structure interaction considering maintained load, remoulding and consolidation.

In summary, the framework provides accurate assessments for soil-structure interaction problems involving maintained load, remoulding and reconsolidation. It is a useful method to simulate cyclic penetrometer tests and practical field operations considering a 'whole-life' loading history. It has the potential to bridge between advanced in situ tests and 


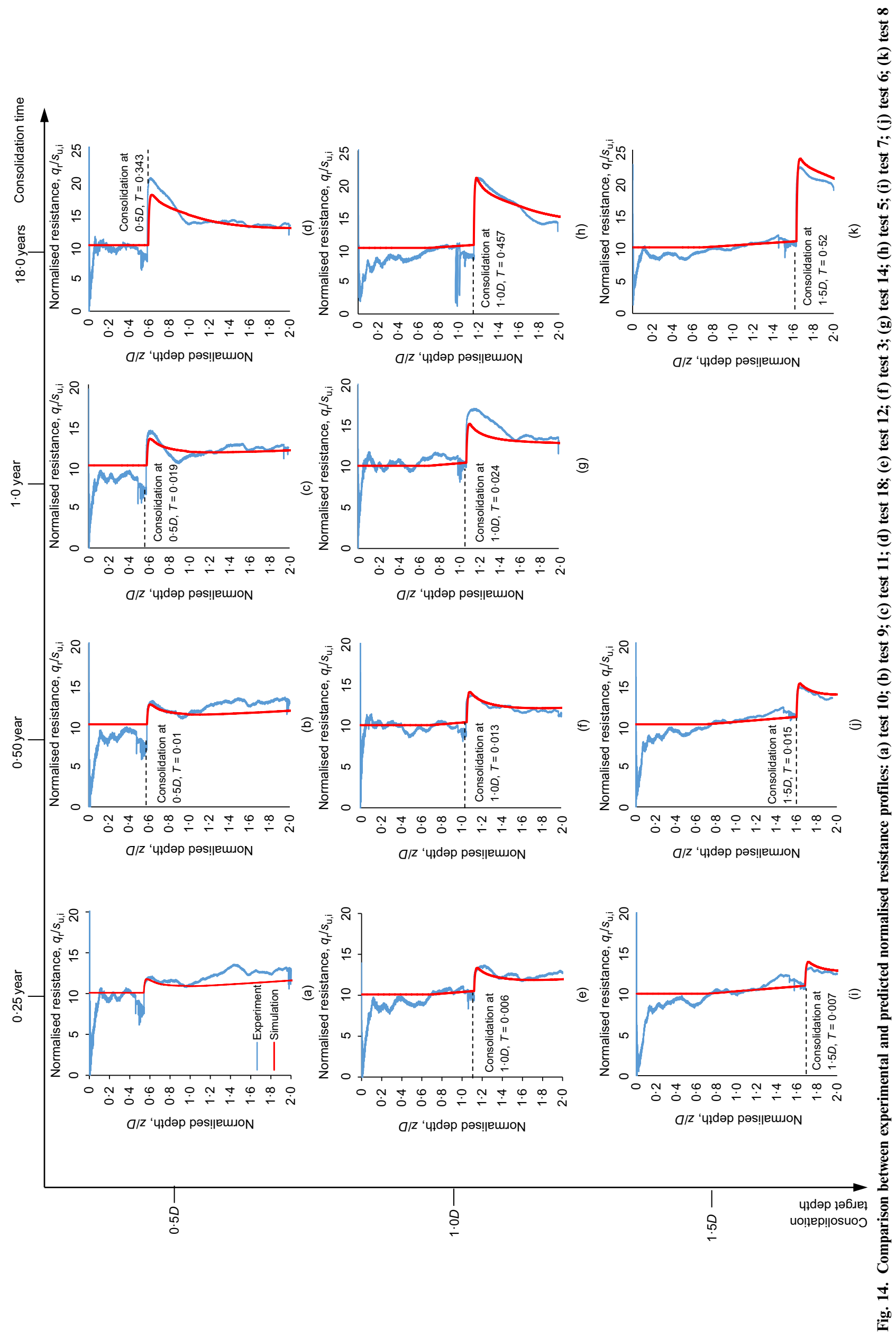




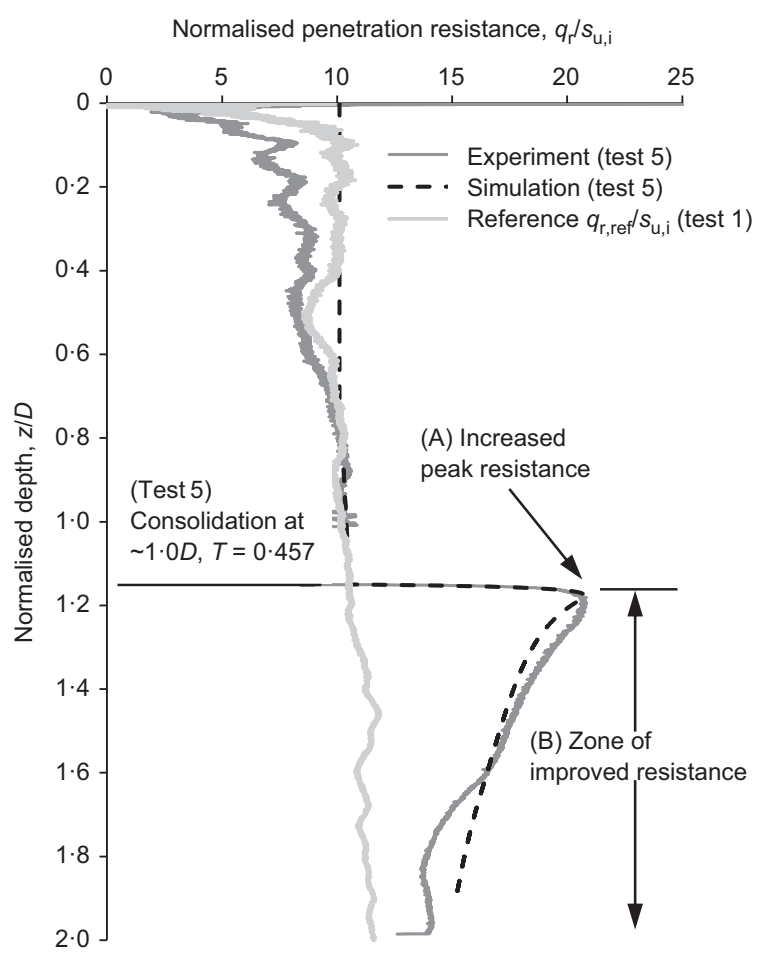

Fig. 15. Improved peak resistance and zone of improved resistance due to consolidation (test 5)

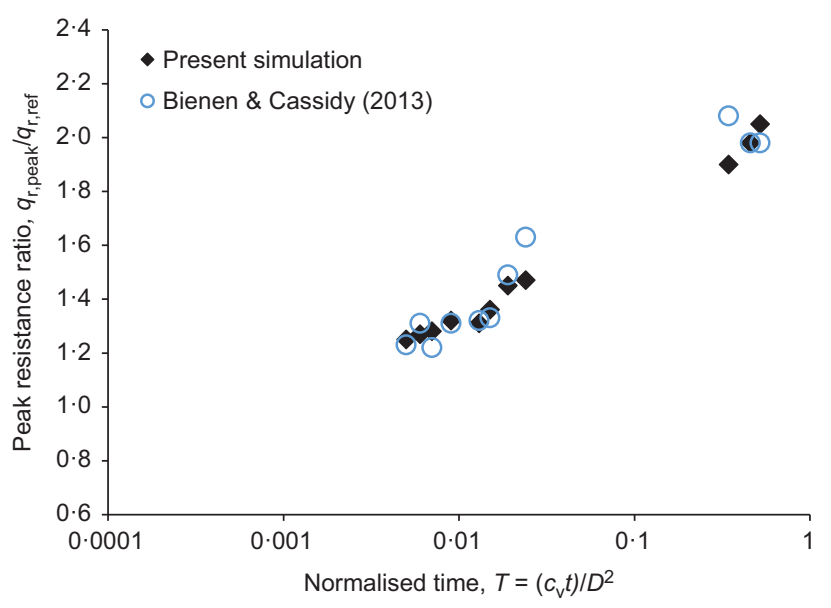

Fig. 16. Comparison between experimental and predicted peak resistance ratios (all simulation cases)

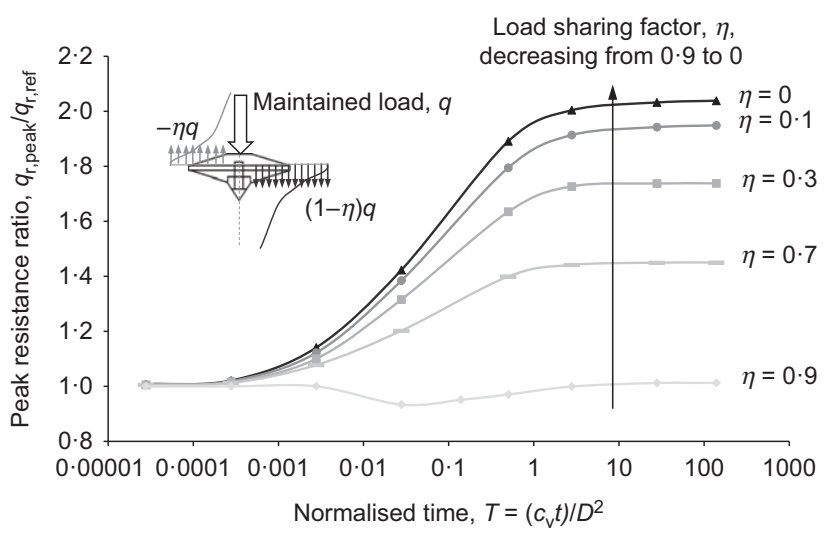

Fig. 17. Effect of changing load sharing factor $(\eta=0$ to $0 \cdot 9)$ (the simulation case at $z \sim 1.0 D$ with maintained load, $q=131.9 \mathrm{kPa}$ ) predictions for foundation design, and confidence will grow as further cases are used to demonstrate and refine the framework.

\section{ACKNOWLEDGEMENTS}

The first author acknowledges his research studentship support from the University of Western Australia (UWA). The second author acknowledges the support from Shell through the Shell Chair in Offshore Engineering at UWA. This work was supported by the ARC Industrial Transformation Research Hub for Offshore Floating Facilities, which is funded by the Australia Research Council, Woodside Energy, Shell, Bureau Veritas and Lloyds Register (grant no. IH140100012).

\section{NOTATION}

$b$ peak strength parameter, $k_{\Phi}(\hat{z})=\operatorname{OCR}(\hat{z})^{b}$

$c_{\mathrm{v}}$ coefficient of consolidation

$D$ diameter of penetrating object

$G_{\mathrm{s}} \quad$ specific gravity

$I_{\sigma}$ influence factor for vertical stress distribution under maintained load

$K$ tangent stiffness

$K_{\max }$ maximum tangent stiffness adopted at the last reversal in direction

$k_{\Phi} \quad$ strength parameter multiplier

$m$ parameter for dissipation rate

$N_{\mathrm{c}}$ bearing capacity factor

$p$ parameter for pore pressure generation rate

$q$ maintained load

$q_{\mathrm{r}}$ penetration resistance

$q_{\mathrm{r} \text {,peak }}$ peak penetration resistance after reconsolidation

$S_{\mathrm{t}, \mathrm{cyc}} \quad$ cyclic soil sensitivity

$s_{\mathrm{u}}$ undrained shear strength

$s_{\mathrm{u}}(\bar{z}) \quad$ undrained shear strength profile

$s_{\mathrm{u}, \mathrm{av}}$ average undrained shear strength

$s_{\mathrm{u}, \mathrm{c}}$ consolidated soil strength

$s_{\mathrm{u}, \mathrm{cyc}} \quad$ cyclic undrained shear strength

$s_{\mathrm{u}, \mathrm{i}}$ in situ undrained shear strength

$s_{u \text { mob }}$ mobilised undrained shear strength

$\left[s_{\mathrm{u}} / \sigma_{\mathrm{v} 0}^{\prime}\right]_{\mathrm{NC}}$ normally consolidated undrained strength ratio

$T$ dimensionless time factor

$T_{50}$ dimensionless time factor for $50 \%$ dissipation of the initial excess pore pressure

$t$ reconsolidation period

$U$ degree of dissipation

$u_{\mathrm{e}}(\bar{z}) \quad$ excess pore pressure profile

$u_{\mathrm{e}, \max }(\bar{z})$ maximum excess pore pressure profile

$u_{\mathrm{e}, \mathrm{r}}(\bar{z})$ remaining potential excess pore pressure profile

$v$ specific volume

$v_{\text {initial }}$ initial specific volume

$v_{\mathrm{p}}$ penetration velocity of the object

$v_{\mathrm{s}}(\hat{z})$ strength influence zone function

$z$ soil depth

$\hat{z}$ normalised soil depth, $z / D$

$z_{\mathrm{m}} \quad$ depth of reference point of penetrating object below soil surface

$\hat{z}_{\mathrm{m}} \quad$ normalised depth, $z_{\mathrm{m}} / D$

$\alpha$ extent of strength influence zone

$\beta$ extent of strain influence zone

$\Gamma_{\mathrm{NCL}}$ specific volume, $v, \sigma_{\mathrm{v}}^{\prime}=1 \mathrm{kPa}$ on the normal consolidation line

$\gamma^{\prime} \quad$ soil effective unit weight

$\varepsilon$ cumulative (absolute) shear strain

$\varepsilon_{95, \Phi}$ peak strength ductility parameter

$\varepsilon_{99}$ cumulative (absolute) shear strain required for a degree of remoulding equal to $99 \%$

$\zeta$ non-linear tangent stiffness parameter

$\eta \quad$ load sharing factor

$\kappa$ gradient of the unload-reload line

$\Lambda$ plastic volumetric strain ratio

$\lambda$ gradient of the normal consolidation line 
$\mu(\hat{z}) \quad$ strain influence distribution function

$\sigma_{\mathrm{v}}^{\prime} \quad$ vertical effective stress

$\sigma_{\mathrm{v}, \mathrm{eqm}}^{\prime}$ equilibrium vertical effective stress

$\sigma_{\mathrm{vc}}^{\prime}$ pre-consolidation stress

$\sigma_{\mathrm{v}, \mathrm{NCL}}^{\prime} \quad$ vertical effective stress at normal consolidation line

$\sigma_{\mathrm{v}, \mathrm{RSL}}^{\prime} \quad$ vertical effective stress at remoulded strength line

$\sigma_{\mathrm{v} 0}^{\prime} \quad$ in situ geostatic effective stress

$\Phi$ lumped strength parameter

$\Phi_{\text {steady }}$ steady value of lumped strength parameter

$\chi \quad$ characteristic pressure

$\Psi$ normalised vertical distance between the object and a given soil horizon

\section{REFERENCES}

Amodio, A., Chang, T. M., Kong, V. \& Erbrich, C. (2015). The effects of jack-up installation procedures on spudcan capacity in offshore carbonate sediments. In Frontiers in offshore geotechnics - ISFOG III, Oslo, Norway (ed. V. Meyer), pp. 1253-1260. Boca Raton, FL, USA: CRC Press.

Andersen, K. H. (2015). Cyclic soil parameters for offshore foundation design. In Frontiers in offshore geotechnics ISFOG III, Oslo, Norway (ed. V. Meyer), pp. 3-82. London, UK: Taylor \& Francis Group.

Andersen, K. H., Kleven, A. \& Heien, D. (1988). Cyclic soil data for design of gravity structures. J. Geotech. Engng, ASCE 114, No. 5, 517-539.

Atkinson, J. H. (2000). Non-linear soil stiffness in routine design. Géotechnique 50, No. 5, 487-508, https://doi.org/10.1680/ geot.2000.50.5.487.

Bienen, B. \& Cassidy, M. J. (2013). Set-up and resulting punchthrough risk of jack-up spudcans during installation. J. Geotech. Geoenviron. Engng, ASCE 139, No. 12, 2048-2059.

Bienen, B., Gaudin, C. \& Cassidy, M. J. (2010). Centrifuge study of the bearing capacity increase of a shallow footing due to preloading. In Physical modelling in geotechnics - ICPMG 2010 (eds S. Springman, J. Laue and L. Seward), vol. 2, pp. 1019-1024. Boca Raton, FL, USA: CRC Press.

Boussinesq, J. (1885). Application des potentiels à l'étude de l'équilibre et du mouvement des solides élastiques: mémoire suivi de notes étendues sur divers points de physique mathématique et d'analyse. Paris, France: Gauthier-Villars (in French).

Bransby, M. F. (2002). The undrained inclined load capacity of shallow foundations after consolidation under vertical loads. In Numerical models in geomechanics - NUMOG VIII (eds G. N. Pande and S. Pietruszczak), pp. 431-437. Boca Raton, FL, USA: CRC Press.

Chatterjee, S., White, D. J. \& Randolph, M. F. (2013). Coupled consolidation analysis of pipe-soil interactions. Can. Geotech. J. 50, No. 6, 609-619.

Cocjin, M. L., Gourvenec, S. M., White, D. J. \& Randolph, M. F. (2017). Theoretical framework for predicting the response of tolerably mobile subsea installations. Géotechnique 67, No. 7, 608-620, https://doi.org/10.1680/jgeot.16.P.137.

Corti, R., Gourvenec, S. M., Randolph, M. F. \& Diambra, A. (2017). Application of a memory surface model to predict whole-life settlements of a sliding foundation. Comput. Geotech. 88, 152-163.

Einav, I. \& Randolph, M. F. (2005). Combining upper bound and strain path methods for evaluating penetration resistance. Int. J. Numer. Methods Engng 63, No. 14, 1991-2016.

Fu, D., Gaudin, C., Tian, C., Bienen, B. \& Cassidy, M. J. (2015). Effects of preloading with consolidation on undrained bearing capacity of skirted circular footings. Géotechnique 65, No. 3, 231-246, https://doi.org/10.1680/geot.14.P.2120.
Gourvenec, S. \& Randolph, M. F. (2010). Consolidation beneath circular skirted foundations. Int. J. Geomech. 10, No. 1, 22-29.

Gourvenec, S., Vulpe, C. \& Murphy, T. G. (2014). A method for predicting the consolidated undrained bearing capacity of shallow foundations. Géotechnique 64, No. 3, 215-225, https://doi.org/10.1680/geot.13.P.101.

Gourvenec, S. G., Feng, X., Randolph, M. F. \& White, D. J. (2017). A toolbox of technologies to optimise subsea foundation design. Proceedings of the offshore technology conference, Houston, TX, USA, paper OTC 27703.

Hodder, M. S., White, D. J. \& Cassidy, M. J. (2009). Effect of remolding and reconsolidates on the touchdown stiffness of a steel catenary riser: Observations from centrifuge modelling. Proceedings of the offshore technology conference, Houston, TX, USA, paper OTC 19871-PP.

Hodder, M. S., White, D. J. \& Cassidy, M. J. (2013). An effective stress framework for the variation in penetration resistance due to episodes of remoulding and reconsolidation. Géotechnique 63, No. 1, 30-43, https://doi.org/10.1680/geot. 9.P.145.

Hossain, M. S. \& Randolph, M. F. (2009). New mechanism-based design approach for spudcan foundations on single layer clay. J. Geotech. Geoenviron. Engng 135, No. 9, 1264-1274.

Janbu, N. (1985). Soil models in offshore engineering. Géotechnique 35, No. 3, 241-281, https://doi.org/10.1680/geot. 1985.35.3.241.

Kohan, O., Gaudin, C., Cassidy, M. J. \& Bienen, B. (2014). Spudcan extraction from deep embedment in soft clay. Appl. Ocean Res. 48, 126-136.

Kohan, O., Cassidy, M. J., Gaudin, C. \& Bienen, B. (2016). Experimental investigation of the effect of cyclic loading on spudcan extraction. J. Offshore Mech. Arctic Engng 138, No. 2, 021301(1)-021301(10).

Lehane, B. M. \& Jardine, R. J. (2003). Effects of long-term pre-loading on the performance of a footing on clay. Géotechnique 53, No. 8, 689-695, https://doi.org/10.1680/geot. 2003.53.8.689.

Martin, C. M. \& Randolph, M. F. (2006). Upper-bound analysis of lateral pile capacity in cohesive soil. Géotechnique 56, No. 2, 141-145, https://doi.org/10.1680/geot.2006.56.2.141.

Muir Wood, D. (1990). Soil behaviour and critical state soil mechanics. Cambridge, UK: Cambridge University Press.

Palmer, A. (1997). Geotechnical evidence of ice scour as a guide to pipeline burial depth. Can. Geotech. J. 34, No. 6, $1002-1003$.

Purwana, O. A., Leung, C. F., Chow, Y. K. \& Foo, K. S. (2005). Influence of base suction on extraction of jack-up spudcans. Géotechnique 55, No. 10, 741-753, https://doi.org/10.1680/ geot.2005.55.10.741.

Puzrin, A. M. \& Burland, J. B. (1998). Non-linear model of small-strain behaviour of soils. Géotechnique 48, No. 2, 217-233, https://doi.org/10.1680/geot.1998.48.2.217.

Schofield, A. N. \& Wroth, C. P. (1968). Critical state soil mechanics. London, UK: McGraw-Hill.

Stewart, D. P. (1992). Lateral loading of piled bridge abutments due to embankment construction. $\mathrm{PhD}$ thesis, The University of Western Australia, Perth, Australia.

Stewart, D. P. \& Randolph, M. F. (1991). A new site investigation tool for the centrifuge. In Proceedings of international conference on centrifuge modelling, centrifuge '91, Boulder (eds H. Y. Ko and F. G. McLean), pp. 531-538. Rotterdam, the Netherlands: Balkema.

Stewart, D. P., Boyle, R. S. \& Randolph, M. F. (1998). Experience with a new drum centrifuge. In Proceedings of international conference on centrifuge modelling, centrifuge '98, Tokyo, Japan, vol. 1 , pp. $35-40$. 